\title{
Highlights in the Solid-Phase Organic Synthesis of Natural Products and Analogues
}

\author{
Vera Lucia Eifler-Lima, ${ }^{* a}$ Cedric S. Graebin, ${ }^{\#, a}$ Flavia De Toni Uchoa, ${ }^{a}$ \\ Patrícia D. Duarte ${ }^{b}$ and Arlene G. Corrêa*,b
}

\author{
${ }^{a}$ Laboratório de Síntese Orgânica Medicinal - LaSOM, Faculdade de Farmácia, Universidade \\ Federal do Rio Grande do Sul, Avenida Ipiranga, 2752/705, 90610-000 Porto Alegre-RS, Brazil \\ ${ }^{b}$ Laboratório de Sintese de Produtos Naturais, Departamento de Química, Universidade Federal de \\ São Carlos, Rodovia Washington Luis km 235, CP 676, 13565-905 São Carlos-SP, Brazil
}

\begin{abstract}
Neste trabalho nós apresentamos uma revisão sobre a síntese em fase sólida de metabólitos secundários, tais como alcalóides, poliaminas, esteróides, terpenos e flavonóides, descritos na literatura a partir de 2000. Um número considerável de rotas sintéticas elegantes e desafiadoras, usando suportes sólidos, será discutido.
\end{abstract}

In this manuscript, we disclose solid-phase organic syntheses (SPOS) of small-molecules of some secondary metabolites, such as alkaloids, polyamines, steroids, terpenes, and flavonoids, described in the literature since 2000. A number of elegant, efficient and challenging syntheses on solid support will be presented.

Keywords: solid-phase organic synthesis, combinatorial chemistry, natural products, secondary metabolites

\section{Introductioon}

Combinatorial Chemistry, which came to light in the early 90 s, is the art and science of synthesizing and testing compounds for bioactivity en masse, instead of one by one, the aim being to discover drugs and materials more quickly and inexpensively than was formerly possible. ${ }^{1}$ The combinatorial methodologies applying to the medicinal chemistry purposes try to incorporate elements capable to furnish a library with both diversity and drug likeness properties in order to shorten time and costs. Combinatorial chemistry has changed the paradigms of drug discovery because with the automatized and miniaturized synthesis, the research time consuming is shortened, rapidly leading to a library of analogues substances with different functional groups or conformational architectures.

The solid-phase organic synthesis (SPOS) has emerged as a powerful tool in the synthesis of small molecules intending to exploit combinatorial chemistry to discover new hits. ${ }^{2}$ In SPOS, ${ }^{3}$ the solid support-bound substrates are

*e-mail: eifler@farmacia.ufrgs.br; agcorrea@ufscar.br

\# Present address: Departamento de Química, Instituto de Ciências Exatas, Universidade Federal Rural do Rio de Janeiro - UFRRJ - BR 465, km 7, 23890-000 Seropédica-RJ, Brazil elaborated synthetically by using an excess of reagents to drive reactions to completion. Desired products can then be isolated easily by simple filtration and removed from the support material. In SPOS, the substrate is coupled to a chemically inert insoluble polymer (resin or lantern) by a covalent bond. This bond must remain stable during the whole chemical process (the orthogonally principle ${ }^{1}$ ), allowing the cleavage of the product from the resin (e.g. by hydrolysis or nucleophilic attack) at the end of the synthetic pathway.

The solid-phase has a principal advantage upon the synthesis carried out in solution, the facility in the purification process which can allow the automation of the whole synthesis. Moreover, the SPOS presents additional advantages: the possibility of using excess of reagents to assure the completion of reactions and the "pseudodilution" effect. ${ }^{4}$

Despite of these advantages, SPOS also presents some important drawbacks: it can be difficult to adapt some conventional solution phase chemistry to a solid-phase format and the progress of solid-phase reactions can be difficult to monitor. An alternative is the use of polymersupport reagents, catalysts, and cleanup agents (scavengers), which facilitate reactions of substrates in solution. 
The SPOS is an effective tool for organic synthesis of molecules with low molecular mass. Conceived by Bruce Merrifield for the peptide synthesis, ${ }^{2}$ more than four decades ago, the SPOS have had its action field increased towards polifunctionalized molecules synthesis and medicinal chemistry. Nowadays SPOS grows up with the development of new resins, linkers, synthesizers, methods to monitoring reactions and resins for scaling up. The SPOS saves time, one of the most important feature at the initial stage of a new drug discovery programs and, in fact, SPOS made combinatorial chemistry successfully and feasible.

Natural products (NPs) are very important for human therapy due to their ability to modulate many pharmacological events. The use of NP in medicine is as older as human civilization. ${ }^{5}$ The first NPs isolated from natural sources in the $19^{\text {th }}$ century were the alkaloids, since then, hundreds of bioactive compounds have been isolated from plants, animal or microorganisms with different architectures, presenting high chemical diversity like: terpenes, coumarins, flavonoids, acetogenins and many others.

The true inventor of combinatorial chemistry is nature, with the generation of molecules with all possible structures: sophisticated or simple compounds. ${ }^{6}$ However, we have few examples of "natural drugs" (templates) which are formulated for ready availability as medicine. ${ }^{7}$ In the majority of cases the "natural drugs" must be chemically modified in order to improve their pharmacological profile. ${ }^{8}$ Sometimes the medicinal chemist synthesizes structural analogs because its pharmacological profile cannot be appropriate to the target, in function of several aspects from biological, chemical or even physic-chemical nature. Actually, the medicinal chemists employ natural products as a source of potentially bioactive compounds (hits) for drug discovery or even as scaffolds for chemical diversification employing numerous options for the synthesis of a wide array of structural variations, like solid-phase synthesis as well as combinatorial approaches. They can synthesize derivatives more potent than the template, with higher druglike properties or with new pharmacological activities not detected before. Thus, new routes of solid-phase synthesis are drawn from three general strategies: $i$ ) employing natural products as scaffold, that is, anchoring on solid support for chemical changes, ii) use of building blocks linked to the solid support for synthesize natural products and analogs, and iii) the total synthesis of natural products.

In this manuscript, we disclose SPOS of smallmolecules of some secondary metabolites, in the literature since 2000, employing those strategies. A number of elegant, efficient and challenger synthesis on solid support will be described.

\section{Alkaloids}

Alkaloids are one of the most important classes of natural products due to their ability to modulate many pharmacological events. The earliest alkaloids isolated from natural sources in the 19th century are still used in therapy (e.g., morphine, quinine, or atropine). After that, many alkaloids with different chemical structures were isolated, contributing to the discovery of new and important drugs. Because of this, the synthesis of alkaloids has become an important milestone for medicinal chemistry, as illustrated by the numerous synthetic routes and methods found in literature in order to facilitate their use in pharmaceutical production.

In 2000, Wang and Ganesan ${ }^{9}$ published the total solid-phase synthesis of the fumiquinazoline alkaloids. Commercially available Wang resin loaded with FmocL-Trp 1 was deprotected and coupled with anthranilic acid in the presence of 1-(3-dimethylaminopropyl)-3ethylcarbodiimide (EDC) as activating agent, followed by coupling with Fmoc-Gly in pyridine. Dehydrative cyclization of linear tripeptide $\mathbf{3}$ was carried out with 10 equiv. of triphenylphosphine. The final reaction was piperidine mediated deprotection of the Fmoc group and rearrangement of oxazine $\mathbf{4}$ to amidine carboxamide $\mathbf{5}$. After washing, the resin was refluxed in a mixture of acetonitrile/dichloroethane to induce cyclization and cleavage furnishing (+)-glyantrypine 6 (Scheme 1).

Sato et al. ${ }^{10}$ synthesized fourteen 4 -quinolinones by aqueous ammonia treatment of the flavylium salts $\mathbf{8}$ obtained by the three-component condensation reaction of acetophenones, aldehydes, and ethyl orthoformate on a solid support with excellent purity and in overall yields of $11-59 \%$ (Scheme 2).

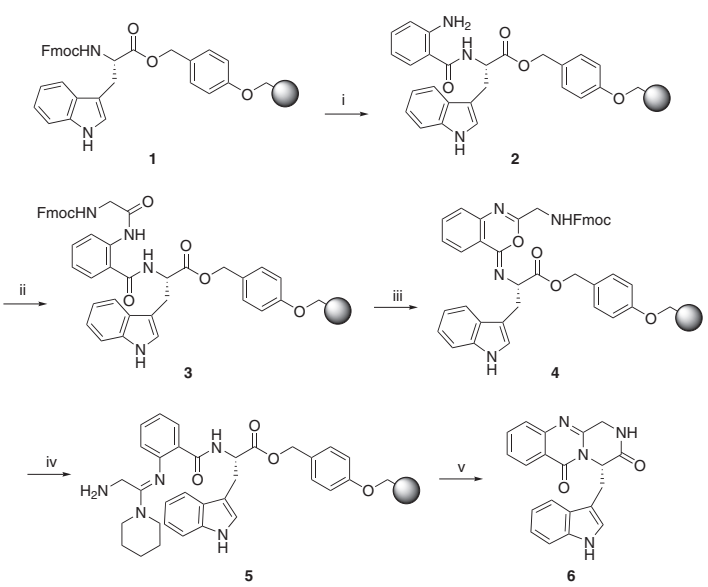

Reagents and conditions: i) (a) piperidine; (b) anthranilic acid (10 equiv.), EDC (12 equiv.); ii) Fmoc-Gly-Cl (7 equiv.), pyridine (15 equiv.); iii) $\mathrm{Ph}_{3} \mathrm{P} /$ $\mathrm{I}_{2} / \mathrm{EtN}(i-\mathrm{Pr})_{2}\left(11 / 11 / 22\right.$ equiv.); iv) piperidine; v) $\mathrm{MeCN} / \mathrm{ClCH}_{2} \mathrm{CH}_{2} \mathrm{Cl}$ (1:1), reflux overnight.

Scheme 1. 


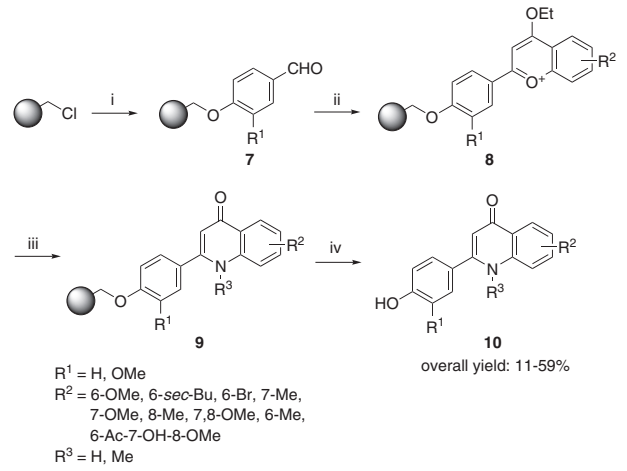

Reagents and conditions: i) $p$-hidroxybenzaldehydes, NaH, DMF, $80{ }^{\circ} \mathrm{C}$; ii) acetophenones, $\mathrm{HC}(\mathrm{OEt})_{3}, \mathrm{CF}_{3} \mathrm{SO}_{3} \mathrm{H}, \mathrm{CH}_{2} \mathrm{Cl}_{2}, \mathrm{rt}$; iii) $\mathrm{NH}_{3}, \mathrm{rt}$; iv) $\mathrm{CF}_{3} \mathrm{CO}_{2} \mathrm{H}, \mathrm{CH}_{2} \mathrm{Cl}_{2}$

\section{Scheme 2.}

Wang and $\mathrm{Sim}^{11}$ reported the synthesis of the quinazoline alkaloids verrucine A (18) and B (21) (Scheme 3). Starting with Fmoc-L-Gln(Trt)-Sasrin-resin 11, the Fmoc was removed using piperidine, and the resulting amino resin was coupled with anthranilic acid to give peptide 12. The anthranilamide 12 was initially acylated with Fmoc-Lphenylalanine acid chloride. Due to the highly acid labile property of the Sasrin resin, the reaction solution was kept neutral to minimize the possible cleavage of the resin. The linear peptide 13a was dehydrated to give benzoxazine $\mathbf{1 4 a}$, which was further deprotected and transformed to the amidine intermediate 15a. Cyclization of $\mathbf{1 5 a}$ in refluxing $\mathrm{MeCN}-\mathrm{Cl}\left(\mathrm{CH}_{2}\right)_{2} \mathrm{Cl}$ provided $\mathrm{N}$-trityl verrucine $\mathrm{A} \mathbf{1 7 a}$ as the

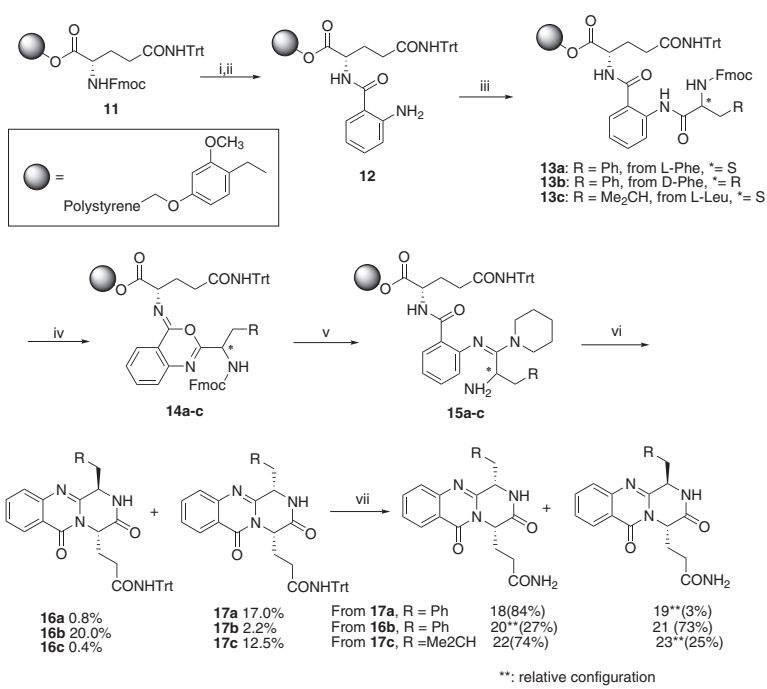

Reagents and conditions: i) $20 \%$ piperidine in DMF, $15 \min (2 \times)$.ii) EDC (13.4 equiv.), anthranilic acid (12.1 equiv.), DMF (method A) or NMP (method B), r.t. 19 h. For 13a-17a: iii) pyridine (7.9 equiv.), Fmoc-L-Phe-Cl (5.1 equiv), $\mathrm{CH}_{2} \mathrm{Cl}_{2}$, r.t. $13 \mathrm{~h}$, workup; repeat once in $\mathrm{MF}$. iv) $\mathrm{Ph}_{3} \mathrm{P}$ (12.0 equiv.), $\mathrm{I}_{2}$ (11.1 equiv.), $\mathrm{Et}(i-\mathrm{Pr})_{2} \mathrm{~N}$ (25.0 equiv.), $\mathrm{CH}_{2} \mathrm{Cl}_{2}$, r.t., overnight $(15 \mathrm{~h})$. v) $20 \%$ piperidine in $\mathrm{CH}_{2} \mathrm{Cl}_{2}$, r.t. $30 \mathrm{~min}$. (vi) $\mathrm{MeCN} /\left(\mathrm{CH}_{2} \mathrm{Cl}\right)_{2}(1: 1)$, reflux overnight. vii) $\mathrm{TFA} / \mathrm{Et}_{3} \mathrm{SiH} / \mathrm{CH}_{2} \mathrm{Cl}_{2}(2: 2: 1)$, r.t., $15 \mathrm{~min}$. major product in $12 \%$ overall yield from 11. Verrucine A (18) was obtained in $84 \%$ yield by deprotecting $\mathbf{1 7 a}$ with $40 \%$ triflouracetic acid (TFA) in $\mathrm{CH}_{2} \mathrm{Cl}_{2}$.

Galanthamine is a tetracyclic alkaloid isolated from Galanthus woronowii and shows potent acetylcholinesterase inhibition. This alkaloid has several points for diversitygenerating reactions. In order to explore the potentialities of galanthamine beyond those previously related to this natural product, Pelish and co-workers ${ }^{12}$ employed the diversity oriented synthesis (DOS) approach to build a library based upon galanthamine core $\mathbf{3 3}$ (Scheme 4). The synthetic strategy chosen was the biomimetic solid-phase synthesis of 2527 galanthamine analogues, starting with the attachment of a tyrosine derivative to a resin through a Si-O bond. The diversity was accomplished by using several building blocks that reacted in $>80 \%$ yield. After six steps, including the cleavage stage, the presence of 2527 out of 2946 (86\%) compounds was confirmed by mass spectrometry. Evaporation of the cleavage reaction solution and resuspension in dimethylsulfoxyde (DMSO) afforded the stock solutions for biological screening.

Huang and Liu described a solid-phase synthesis of a series of $4(1 H)$ quinolones. ${ }^{13}$ A resin-bound cyclic
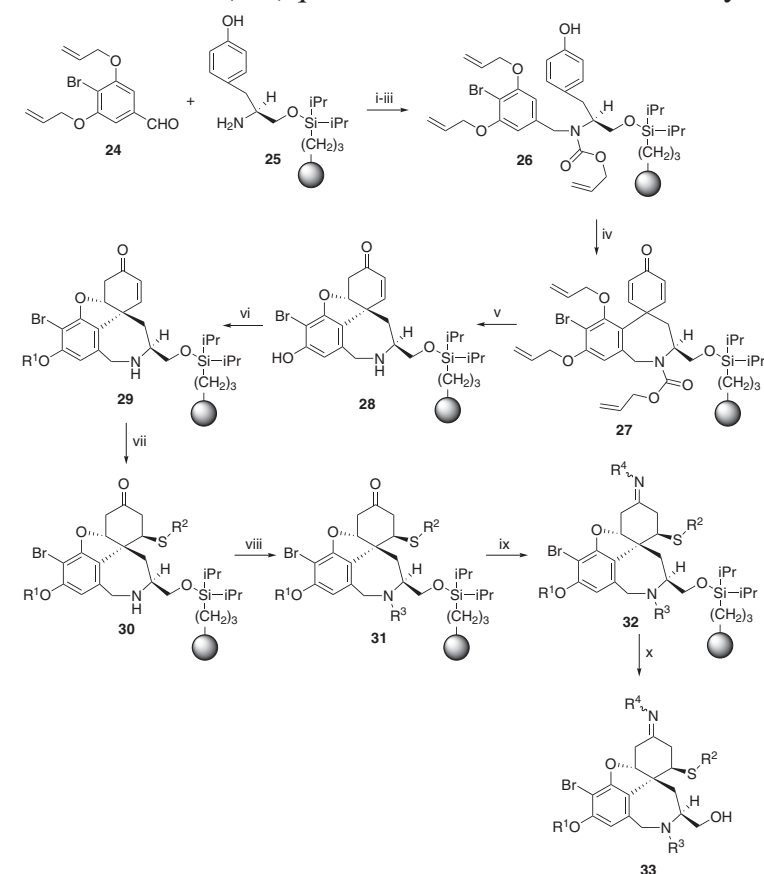

Reagents and conditions: Reagents: i) $\mathrm{CH}\left(\mathrm{OCH}_{3}\right)_{3} \mathrm{CH}_{2} \mathrm{Cl}_{2}$, wash, then $\mathrm{NaBH}_{3} \mathrm{CN}, \mathrm{AcOH}, \mathrm{MeOH}, \mathrm{THF}, 23^{\circ} \mathrm{C}$; ii) allylchloroformate, $i$ - $\mathrm{Pr}_{2} \mathrm{EtN}$, $\mathrm{CH}_{2} \mathrm{Cl}_{2}, 23^{\circ} \mathrm{C}$; iii) piperidine, THF, $23^{\circ} \mathrm{C}$; iv) $\mathrm{PhI}(\mathrm{OAc})_{2},\left(\mathrm{CF}_{3}\right)_{2} \mathrm{CHOH}$, $\mathrm{CH}_{2} \mathrm{Cl}_{2}, 23{ }^{\circ} \mathrm{C}$; v) $\mathrm{Pd}\left(\mathrm{PPh}_{3}\right)_{4}$, morpholine, THF, $23{ }^{\circ} \mathrm{C}$; vi) $\mathrm{R}^{1} \mathrm{OH}, \mathrm{PPh}_{3}$, diisopropyl azodicarboxylate (DIAD), THF, $0{ }^{\circ} \mathrm{C}$, (2x); vii) $\mathrm{R}_{2} \mathrm{SH}^{3}$, 2,6-lutidine, $n$-BuLi, THF, 0 to $40^{\circ} \mathrm{C}$; viii) $\mathrm{R}^{3} \mathrm{CHO}, \mathrm{AcOH}, \mathrm{MeOH}$, THF, then $\mathrm{NaBH}_{3} \mathrm{CN}$ in $\mathrm{MeOH}, 23{ }^{\circ} \mathrm{C}$ or $\mathrm{R}^{3} \mathrm{COCl}, 2$,6-lutidine, $\mathrm{CH}_{2} \mathrm{Cl}_{2}, 23^{\circ} \mathrm{C}$ or $\mathrm{R}^{3} \mathrm{NCO}, \mathrm{CH}_{2} \mathrm{Cl}_{2}, 23{ }^{\circ} \mathrm{C}$; ix) $\mathrm{R}^{4} \mathrm{NH}_{2}, \mathrm{AcOH}, \mathrm{MeOH}, \mathrm{CH}_{2} \mathrm{Cl}_{2}, 23{ }^{\circ} \mathrm{C}$; $\mathrm{x}) \mathrm{HF}$, pyridine, THF, $23^{\circ} \mathrm{C}$, then trimethylsilyl methoxyde (TMSOMe). 
malonic ester has been prepared on Merrifield resin (Scheme 5). Reaction of the cyclic malonic ester $\mathbf{3 7}$ with triethyl orthoformate and subsequent substitution by an arylamine afforded arylaminomethylene cyclic malonic ester preloaded resin 38. A series of $4(1 H)$ quinolones were prepared by thermal cyclization in moderate yields and high purity.

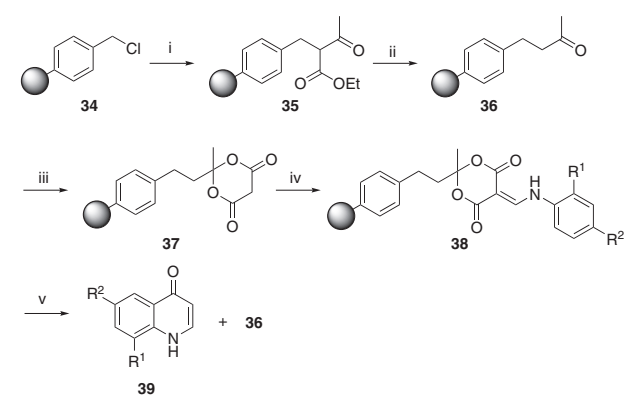

Reagents and conditions: i) sodium ethyl acetoacetate, DMF, $80^{\circ} \mathrm{C}, 16 \mathrm{~h}$; ii) DMSO, $\mathrm{NaCl}, 140^{\circ} \mathrm{C}, 48 \mathrm{~h}$; iii) malonic acid, acetic anhydride, conc. $\mathrm{H}_{2} \mathrm{SO}_{4}$; iv) a. $\mathrm{HC}(\mathrm{OEt})_{3}$, reflux, $6 \mathrm{~h}$; b. substituted anilines, reflux, $20 \mathrm{~h}$; v) thermolysis, $\mathrm{N}_{2}, 240^{\circ} \mathrm{C}, 30 \mathrm{~min}$.

\section{Scheme 5.}

In 2002, Baxendale and co-workers ${ }^{14}$ described the total synthesis of the amaryllidaceae alkaloid (+)-plicamine (49) and its unnatural enantiomer by using solid-supported reagents and scavengers in a multistep sequence of reactions (Scheme 6).

In the same year, Baxendale et al. ${ }^{15}$ demonstrated the rapid construction of a small collection of nicotine derivatives using a range of readily available monomers
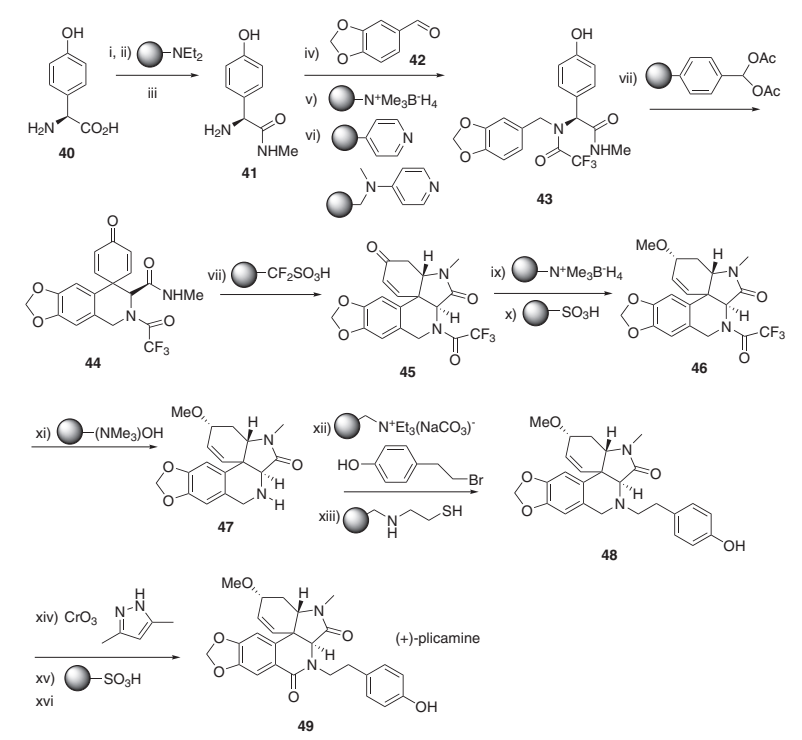

Reagents and conditions: i) TMSCl/ $\mathrm{MeOH}$; iii) $\mathrm{NH}_{2} \mathrm{Me}$; vi) $\left(\mathrm{CF}_{3} \mathrm{CO}\right)_{2} \mathrm{O}$, $\left.\mathrm{CH}_{2} \mathrm{Cl}_{2} ; \mathrm{x}\right)$ TMS-CHN $;$;vi) Clay scavenger.

Scheme 6.
(Scheme 7). They synthesized nornicotine (50) and other functionalized derivatives using solid-supported reagents and scavengers.

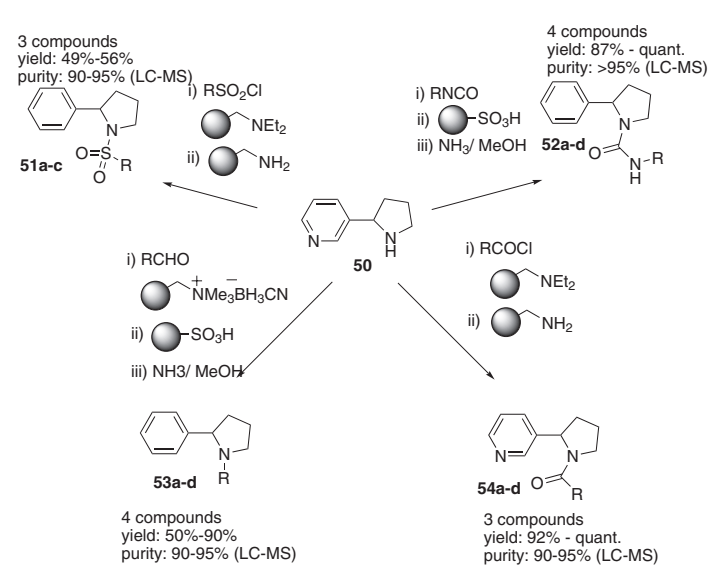

Scheme 7.

Finaru et al. ${ }^{16}$ reported the solid-phase synthesis of the indole core of melatonin analogues under microwave irradiation. The acid-labile Rink linker was chosen for connection of aromatic iodide $\mathbf{5 8}$ to polystyrene. Generation of various indole derivatives $\mathbf{6 2}$ was performed in four steps via a palladium-mediated reaction between 2-iodoaniline $\mathbf{5 9}$ derivatives and functionalized acetylenes 60 (Scheme 8).

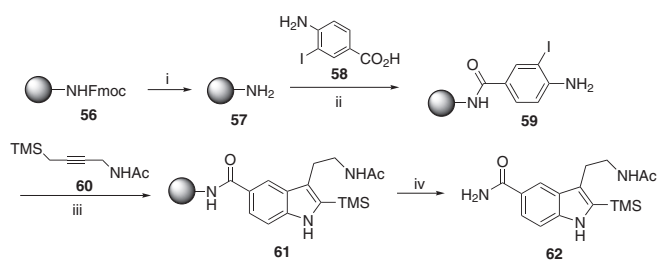

Reagents and conditions: (i) piperidine $20 \%$, dimethylacetamide (DMA), r.t., $60 \mathrm{~min}$; (ii) 61 (4.4 equiv.), O-(benzotriazol-1-yl)- $N, N, N^{\prime}, N^{\prime}$,tetramethyluronium hexafluoroborate (TBTU) (4.4 equiv), $\mathrm{HOBt}$ (2 equiv.), $\mathrm{NEt}_{3}$ (14.4 equiv.), DMAP (1 equiv.), dioxane, microwave (MW), 3 min; (iii) 63 (3-5 equiv.), $\mathrm{Pd}(\mathrm{OAc})_{2}$ ( 0.2 equiv.), $\mathrm{PPh}_{3}$ ( 0.4 equiv.), $\mathrm{LiCl}$ (2 equiv.), $\mathrm{NaOAc}$ (4 equiv.), DMA, MW, $13 \mathrm{~min}$ ( $2 \times$ ); (iv) TFA, 20\%, $\mathrm{CH}_{2} \mathrm{Cl}_{2}$, r.t.

Scheme 8.

In 2004, Nielsen and Meldal ${ }^{17}$ described a highly efficient approach for solid-phase generation of a range of pharmacologically interesting tri- and tetracyclic scaffolds from masked aldehyde building blocks protected as their $N$-Boc-1,3-oxazinanes 65. Subsequently, a quantitative and highly stereoselective Pictet-Spengler reaction takes place by attack of the indole from a neighboring tryptophan, thus appending two new $N$-fused rings to the indole moiety 67. (Scheme 9). Finally, the reaction products may conveniently be released from the solid support polyethylene glycoldimethylacrylamide co-polymer (PEGA) by cleavage of 
the base-labile linker $N, N^{\prime}$-hexamethylene bis(acetamide) (HMBA).

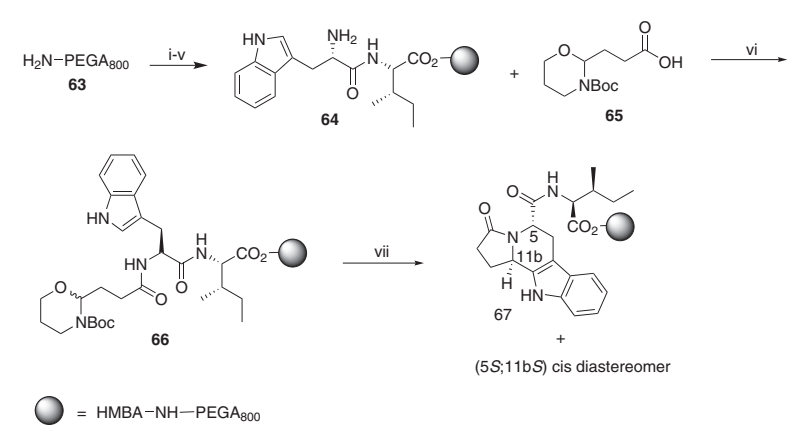

Reagents and conditions: (i) HMBA, TBTU, $N$-ethylmorpholine (NEM), DMF; (ii) Fmoc-Ile-OH, 1-(2-mesitylenesulfonyl)-3-nitro-1H-1,2,4triazole (MSNT), MeIm, $\mathrm{CH}_{2} \mathrm{Cl}_{2}$; (iii) 20\% piperidine (DMF); (iv) FmocTrp-OH, TBTU, NEM, DMF; (v) $20 \%$ piperidine (DMF); (vi) 67a, TBTU, NEM, DMF; (vii) $\mathrm{H}^{+}$(aq) (cis/trans 1:10).

Scheme 9.

An efficient solid-phase synthesis of the pyrrole-based alkaloids lamellarins Q (75) and O (76) using Merrifield resin was published by Marfil et al. ${ }^{18}$ (Scheme 10). Compound 70 was obtained by selective orthodirected bromine/lithium interchange at position 3 by treatment of methyl 3,4-dibromopyrrole-2-carboxylate with $n$-BuLi at low temperature followed by metal-metal interchange using zinc chloride. The organometallic compound $\mathbf{7 0}$ was employed in a $\operatorname{Pd}(0)$-catalysed Negishi cross-coupling reaction with the resinbound iodophenol $\mathbf{6 9}$.

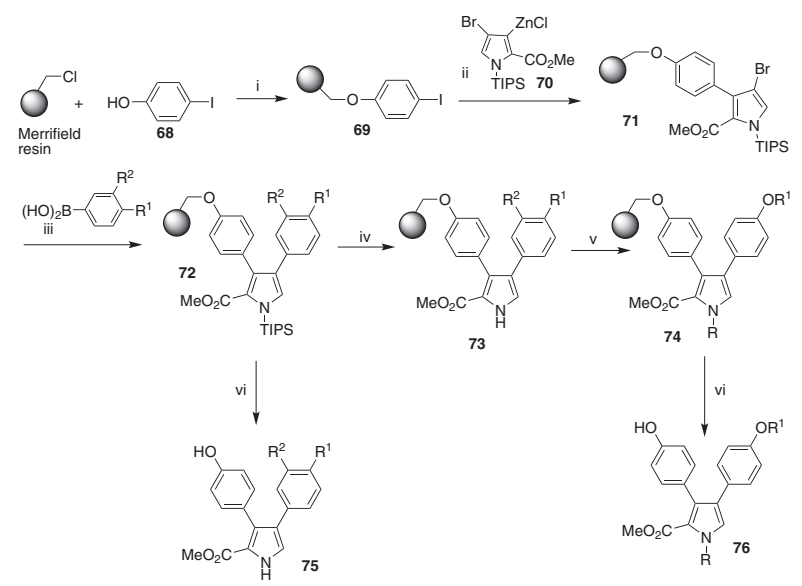

Reagents and conditions: (i) $\mathrm{NaOMe}$, dry DMF, $\mathrm{N}_{2}, 80{ }^{\circ} \mathrm{C}, 24 \mathrm{~h}$; (ii) $\mathrm{Pd}\left(\mathrm{PPh}_{3}\right)_{4}$, dry THF, $\mathrm{N}_{2}$, r.t., 24 h; (iii) aq. $2 \mathrm{M} \mathrm{Na}_{2} \mathrm{CO}_{3}, \mathrm{Pd}\left(\mathrm{PPh}_{3}\right)_{4}$, dioxane, reflux, 21-48 h; (iv) $\mathrm{NH}_{4} \mathrm{~F}, \mathrm{CH}_{2} \mathrm{Cl}_{2} / \mathrm{MeOH}$ (1:1), reflux, $6 \mathrm{~h}$; (v) $\mathrm{NaH}$ (or LDA), dry THF, $\mathrm{N}_{2},-78^{\circ} \mathrm{C}, 24 \mathrm{~h}$; or 18 -crown-6 $(2.5 \mathrm{M}$ in DMF), microwave, $100^{\circ} \mathrm{C}, 30-40 \mathrm{~W}, 2 \mathrm{~min}$; (vi) $\mathrm{AlCl}_{3}$, dry $\mathrm{CH}_{2} \mathrm{Cl}_{2}$, r.t., $3 \mathrm{~h}$.

Scheme 10.

Cironi et al. ${ }^{19}$ have also published the solid-phase synthesis of lamellarins (Scheme 11). Three different polystyrene resins, chloro and hydroxyl Merrifield and Wang resins were tested. At the final step resins were cleaved with a Lewis acid such as $\mathrm{AlCl}_{3}, \mathrm{ZnBr}_{2}$ or TFA in $\mathrm{CH}_{2} \mathrm{Cl}_{2}$, furnishing lamellarin $\mathrm{U}(\mathbf{8 5})$ and analogues.

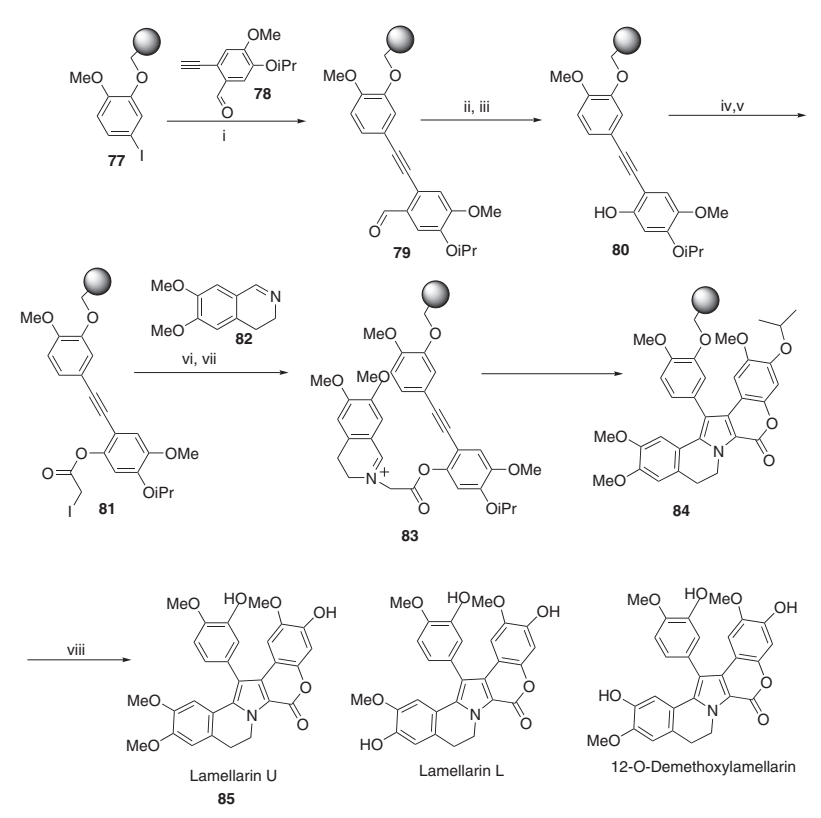

Reagents and conditions: i) $\mathrm{Pd}\left[\left(\mathrm{PPh}_{3}\right)_{2} \mathrm{Cl}_{2}\right]$, Cu THF.Et $\mathrm{N}$; ii) $m$ CPBA, $\mathrm{NaHCO}_{3}, \mathrm{CH}_{2} \mathrm{Cl}_{2}$; iii) $2 \mathrm{M} \mathrm{KOH}, \mathrm{THF}, \mathrm{MeOH}$; iv) $\mathrm{ICH}_{2} \mathrm{COOH}$, DMAP; v) $\mathrm{N}, \mathrm{N}$-diisopropylcarbodiimide (DIPCDI), DMF; vi) $\mathrm{CH}_{2} \mathrm{ClCH}_{2} \mathrm{Cl}$; vii) DIEA reflux; viii) $\mathrm{AlCl}_{3}, \mathrm{CH}_{2} \mathrm{Cl}_{2}$.

\section{Scheme 11.}

Knepper et al. ${ }^{20}$ described the reaction of immobilized $o$-carboxybenzaldehydes $\mathbf{8 6}$ with primary amines at room temperature furnishing imines $\mathbf{8 7}$ formation, which underwent 1,2-addition-cleavage reaction with various nucleophiles, yielding isoindolinones 89 (Scheme 12).

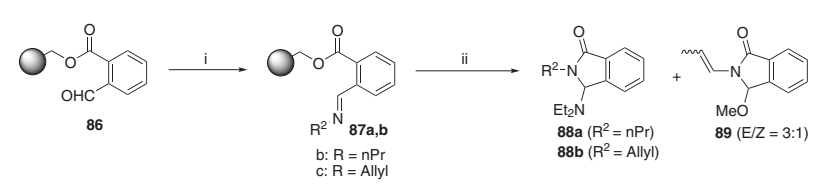

Reagents and conditions; i) $\mathrm{H}_{2} \mathrm{NR}^{2}$, THF, rt, 6h; ii) Nu- THF, reflux, $24 \mathrm{~h}$ $\left(\mathrm{Nu}=\mathrm{NEt}_{2}, \mathrm{OMe}\right)$.

\section{Scheme 12.}

The synthesis of a library of indoline-alkaloid-like polycycles from an enantioenriched aminoindoline was described (Scheme 13). ${ }^{21}$ The intermediate 91 was treated with piperidine to give the tricyclic derivative 92 during the removal of the Fmoc group. The in situ conjugate hetero-Michael reaction was efficient. The mild conditions for this cyclization reaction are highly appealing and attractive to explore its potential in the 
generation of a library. The stereochemical outcome of this reaction was found to be dependent upon the choice of the amino acid. To complete the test sequence in the solid phase, 92 was then subjected to $i$ ) an amide coupling reaction to introduce the second diversity, $i i)$ removal of the Alloc protecting group to give the free amine, and iii) reaction with carboxylic acid chloride to introduce the third diversity and to give $\mathbf{9 3}$. Finally, compounds 94 and 95 were obtained in a ratio varied from 5:1 to 1:1, upon cleavage of the substrates from the support under desilylation conditions.

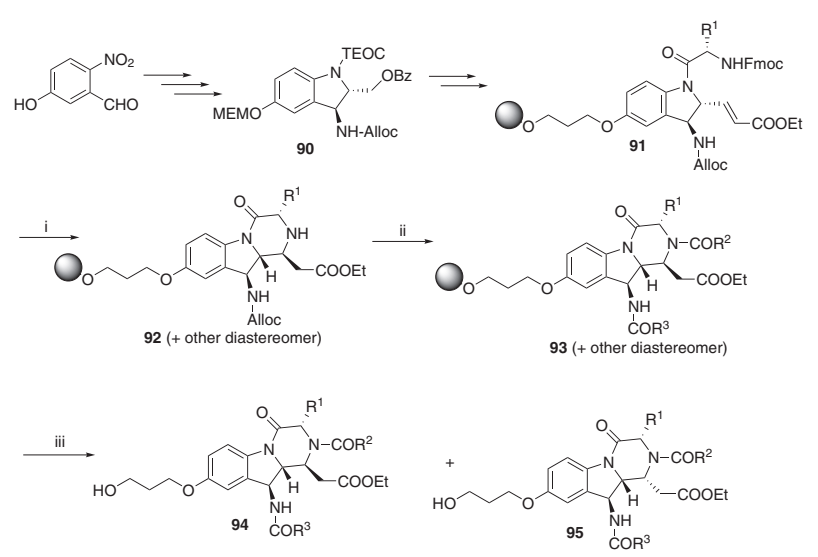

Reagents and conditions: i) $20 \%$ piperidine; ii) $1 . \mathrm{R}_{2} \mathrm{COCl}$, pyridine; $2 \mathrm{Pd}\left(\mathrm{PPh}_{3}\right)_{4} ; 3 . \mathrm{R}_{3} \mathrm{COCl}$, pyridine; iii) pyridine-HF; $80-85 \%$ yield of $\mathbf{9 4}$ and 95.

Scheme 13.

Adriaenssens et al. ${ }^{22}$ described that the use of alkylidenetitanium reagents enable to control the high throughput asymmetric synthesis of 2-substituted piperidines $\mathbf{1 0 2}$ and a rapid access to multiple cyclic imines using solid-phase synthesis (Scheme 14). The Schrock carbenes (97 and $\mathbf{9 8}$ ) generated by reduction of thioacetals, convert resin-bound esters into enol ethers $\mathbf{9 9 .}$ Treatment with acid releases amino ketones to give iminium salts $\mathbf{1 0 0}$ that are cyclized in the presence of $\mathrm{NaOH}$ and TMSCl. Reduction introduces a chiral centre at C-2 of 101, whose absolute stereochemistry is determined by a phenethylamine (PEA) chiral auxiliary.

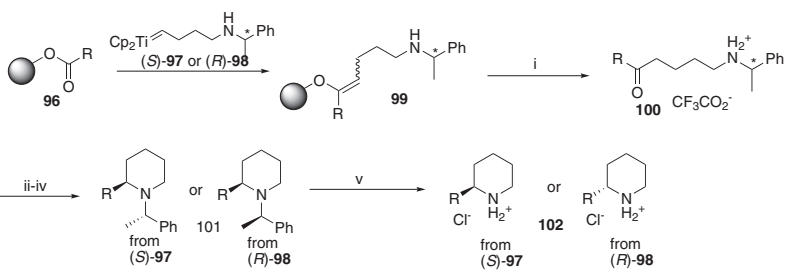

Reagents and conditions: i) $4 \% \mathrm{CF}_{3} \mathrm{CO}_{2} \mathrm{H}$ in $\mathrm{CH}_{2} \mathrm{Cl}_{2}$; ii) $\mathrm{NaOH}(\mathrm{aq})$; iii) TMSCl; iv) $\mathrm{NaBH}(\mathrm{OAc})_{3}$; v) $\mathrm{H}_{2}, \mathrm{Pd} / \mathrm{C}, \mathrm{HCl}, \mathrm{EtOH}, 65^{\circ} \mathrm{C}$.

Scheme 14.
Lee and Park ${ }^{23}$ developed a multistep, practical solidphase strategy for the synthesis of natural product-like diaza-bridged heterocycles $\mathbf{1 0 8}$ and $\mathbf{1 0 9}$ (Scheme 15). A key step in the library synthesis is the tandem acidolytic cleavage with subsequent in situ iminium formation followed by the Pictet-Spengler intramolecular cyclization. This cyclization was regio- and diastereoselective to give final products as single diastereomers in exceptional yields and purities, which was confirmed by NMR structural study and LC/MS analysis.

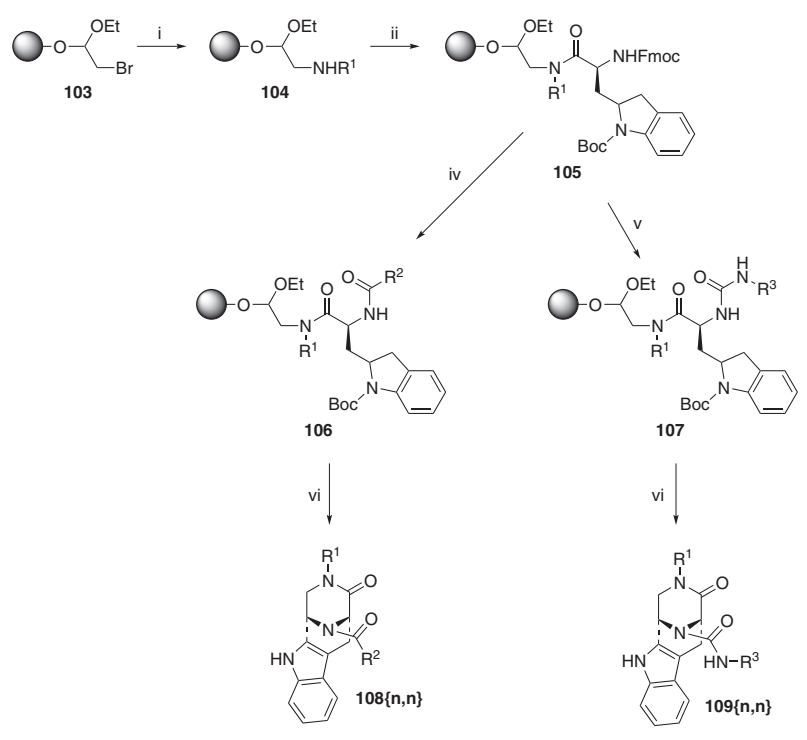

Reagents and conditions: (i) $\mathrm{R}_{1} \mathrm{NH}_{2}, \mathrm{DMSO}, 60^{\circ} \mathrm{C}$; (ii) $\mathrm{Fmoc}(N$-Boc) TrpOH, O-(7-azabenzotriazol-1-yl)- $N, N, N^{\prime}, N^{\prime}$,-tetramethyluronium hexafluorophosphate(HATU), DIPEA, DMF, r.t.; (iv) (a) 25\% piperidine, r.t.; (b) $\mathrm{R}_{2} \mathrm{CO}_{2} \mathrm{H}$, DIC, HOBt, DIPEA, r.t.; (v) $\mathrm{R}_{3} \mathrm{NCO}$, DIPEA, $\mathrm{ClCH}_{2} \mathrm{CH}_{2} \mathrm{Cl}$, r.t.; (vi) neat $\mathrm{HCO}_{2} \mathrm{H}$, r.t.

\section{Scheme 15.}

A 24-member combinatorial library based on the structure of aeruginosin 298-A (115) was synthesized by Doi et al..$^{24}$ utilizing a silyl linker. Attachment of $\mathbf{1 1 0}$ to PS-DESCl provided polymer-supported 111. Removal of the Boc group in 111, followed by condensation with Fmoc-D-Leu-OH using $N$-hydroxybenzotriazole(DIC)$\mathrm{N}$-hydroxybenzotriazole(HOBt), repeated twice, afforded polymer-supported dipeptide $\mathbf{1 1 2}$ in $93 \%$ purity (Scheme 16). The $O$-allyl ester in $\mathbf{1 1 2}$ was removed with $\mathrm{Pd}\left(\mathrm{PPh}_{3}\right)_{4} /$ dimedone. Coupling of the free acid with $(S)-N-\omega, \omega$ '-(ditert-butoxycarbonyl)argininol tert-butyldimethylsilyl ether afforded 113 in 94\% purity. After Fmoc deprotection in 113, a propionic acid derivative was coupled using DIC-HOBt in $14 \mathrm{~h}$. Acid cleavage of the polymer-supported 114 and simultaneous removal of the TBS and Boc groups with $\mathrm{TFA} / \mathrm{CH}_{2} \mathrm{Cl}_{2} / \mathrm{H}_{2} \mathrm{O}$ provided a mixture of aeruginosin $298-\mathrm{A}$ in $66 \%$ purity and its trifluoroacetate derivatives in $25 \%$ 
purity. Then, the crude mixture was treated with polymersupported $N$-methylmorphorine (PS-NMM) to remove the trifluoroacetate providing $\mathbf{1 1 5}$ in $84 \%$ purity. After purification by ODS column chromatography, aeruginosin 298-A was isolated.

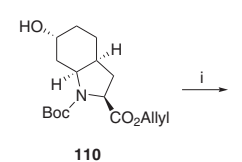

110
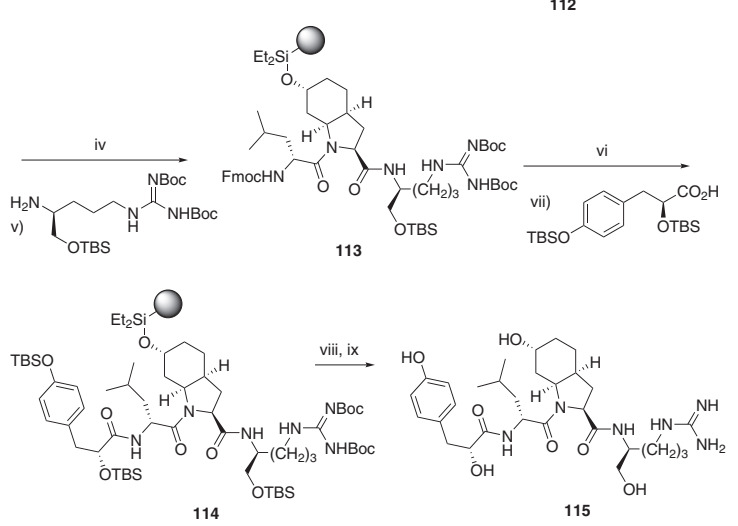

Reagents and conditions: i) PS-SiEt $2 \mathrm{Cl}$, Imidazole, $\mathrm{CH}_{2} \mathrm{Cl}_{2}$; ii) TMSOTf, 2,6-lutidine, $\mathrm{CH}_{2} \mathrm{Cl}_{2}$; iii) Fmoc-D-Leu-OH, DIC, $\mathrm{HOBt}$; iv) $\mathrm{Pd}\left(\mathrm{PPh}_{3}\right)_{4}$, dimedone, THF; v) DIC, HOBt; vi) piperidine, DMF; vii) DIC, $\mathrm{HOBt}$; viii) TFA, $\mathrm{CH}_{2} \mathrm{Cl}_{2}, \mathrm{H}_{2} \mathrm{O}$; ix) PS-NMM, $\mathrm{MeOH}, \mathrm{CH}_{2} \mathrm{Cl}_{2}$.

Scheme 16.

The solid-phase synthesis of fused [2,1-b]quinazolinone alkaloids has been developed for the preparation of vasicinone (124a) and deoxyvasicinone (124b) by two approaches illustrated in the Scheme $17 .{ }^{25}$ Firstly, the resin-linked azido-benzoic acids were coupled with bromo-substituted lactams followed by cyclization in an aza-Wittig reductive cyclization process giving the bromo-

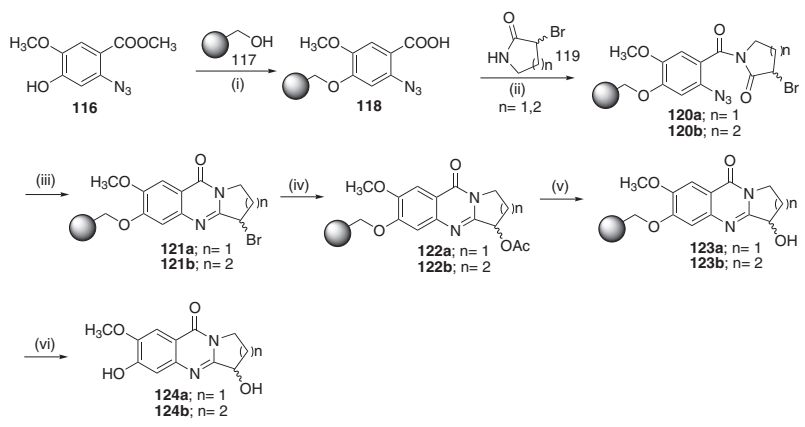

Reagents and conditions: (i) (a) $\mathrm{PPh}_{3}$, DIAD, NMP, 16 h, r.t.; (b) 1 mol L-1 $\mathrm{NaOH}, 1,4$-dioxane, $100^{\circ} \mathrm{C}, 12 \mathrm{~h}$; (ii) $N, N^{\prime}$-dicyclohexylcarbodiimide (DCC), DMAP, $\mathrm{CH}_{2} \mathrm{Cl}_{2}, 12 \mathrm{~h}, 0{ }^{\circ} \mathrm{C}$-r.t.; (iii) $\mathrm{PPh}_{3}$, toluene, 3 h, r.t.; (iv) KOAc, 18 -crown-6-ether, $\mathrm{CH}_{3} \mathrm{CN}, 80^{\circ} \mathrm{C}, 6$ h or DMF, 8 h, r.t.; (v) $\mathrm{K}_{2} \mathrm{CO}_{3}$, THF-MeOH (1:1), $6 \mathrm{~h}$, rt; (vi) TFA, $\mathrm{CH}_{2} \mathrm{Cl}_{2}$, (1:1) 1 h, r.t.

Scheme 17. substituted quinazolinone intermediates (121a-b) which, by subsequent acetylation, hydrolysis and resin cleavage, afford the fused [2,1-b]quinazolinones.

Baxendale et $a l .{ }^{26}$ described a flow process for the multi-step synthesis of the alkaloid natural product $( \pm)$-oxomaritidine (133). This synthesis was mediated through the use of microfluidic pumping systems that drive the material through various packed columns containing immobilized reagents, catalysts, scavengers or catch and release agents. The route involves seven synthetic steps, can generate gram quantities of oxomaritidine in $40 \%$ overall yield and $90 \%$ purity in only one day. Key steps include trapping previously prepared 4-(2-azidoethyl)phenol (126) with a polymer-supported phosphine on a column and subsequently coupling it with 3,4-dimethoxybenzaldehyde (128), which is prepared in a separate channel. The resulting imine intermediate is sequentially converted to an amide $\mathbf{1 3 1}$ in steps that include changing solvents and a palladium-mediated hydrogenation that takes place in a flow-through unit. In the final stages, the third ring of oxomaritidine is formed and the amide is cleaved, promoting a bridging 1,4-addition to give the end product $\mathbf{1 3 3}$ (Scheme 18).

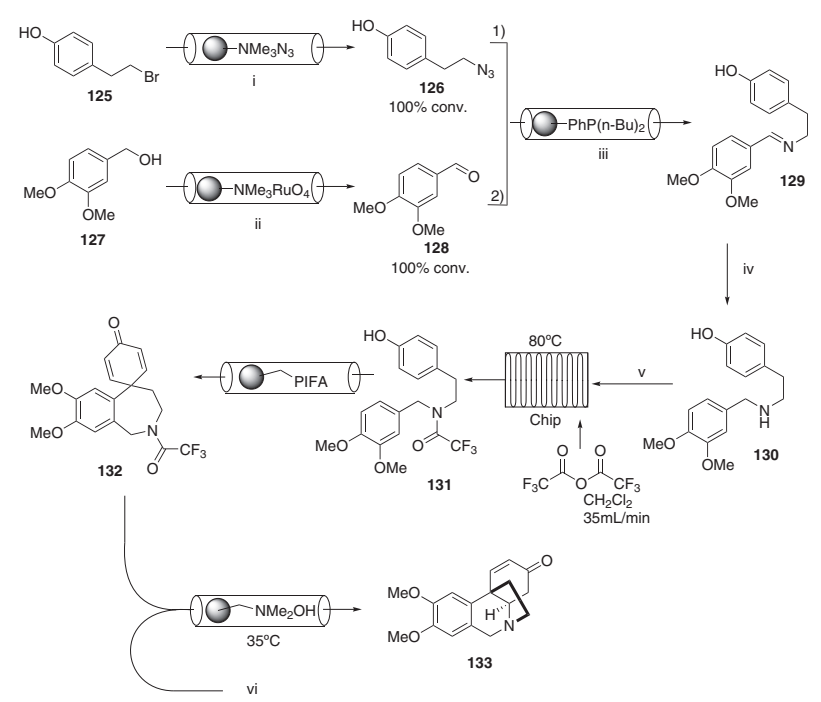

Reagents and conditions: i) $20 \mathrm{eq}, 70^{\circ} \mathrm{C}, \mathrm{CH}_{3} \mathrm{CN}$ : THF (1:1), $50 \mathrm{~mL}$ $\mathrm{min}^{-1}$; ii) 10 eq., THF, r.t., $50 \mathrm{~mL} \mathrm{~min}^{-1}$; iii) 20 eq., 1 r.t., $2.55^{\circ} \mathrm{C}$; iv) flow

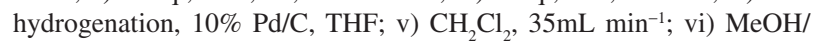
$\mathrm{H}_{2} \mathrm{O}, 4: 1,70 \mathrm{~mL} \mathrm{~min}^{-1}$.

\section{Scheme 18.}

Krchnak and co-workers ${ }^{27}$ described the synthesis of new pyrrole and quinoxalinone analogues. The strategy involved the cycloaddition of piperine, a natural conjugated diene, with polymer supported acyl- and arylnitroso dienophiles 136 (Scheme 19). The arylnitroso dienophiles were prepared immobilized by using ethanolamine to a silyloxy linker. 
Treatment of the nitroarylnitroso HDA adduct $\mathbf{1 3 5}$ with $50 \%$ TFA, triflouracetic acid, was accompanied by ring contraction and formation of pyrrole derivative 136. Subjected HDA adducts 137 to reducing conditions. Treatment with $1 \mathrm{~mol} \mathrm{~L}^{-1}$ $\mathrm{SnCl}_{2} \cdot 2 \mathrm{H}_{2} \mathrm{O}, 1 \mathrm{~mol} \mathrm{~L}^{-1} \mathrm{~N}, \mathrm{~N}$-diisopropylethylamine (DIEA) in 1-methyl-2-pyrrolidinone (NMP) for $2 \mathrm{~h}$ afforded, after cleavage by $50 \%$ TFA, $5 H$-pyrrolo[ $1,2-a$ ]quinoxalin-4-one derivative $\mathbf{1 3 8}$ as the major component.

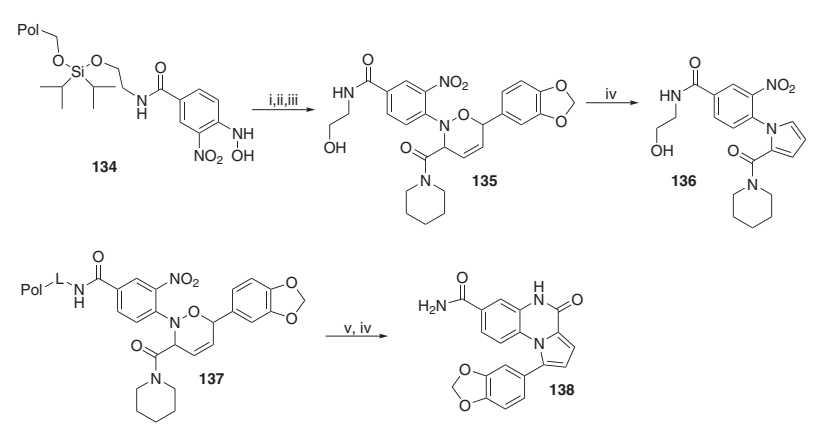

Reagents and conditions: (i) $0.1 \mathrm{M} n$ - $\mathrm{Bu}_{4} \mathrm{NIO}_{4}, \mathrm{CH}_{2} \mathrm{Cl}_{2}$, r.t., $1 \mathrm{~h}$; (ii) piperine, $\mathrm{CH}_{2} \mathrm{Cl}_{2}$, overnight; (iii) $0.1 \mathrm{M}$ tetra- $n$-butylammonium fluoride (TBAF), THF, r.t., $30 \mathrm{~min}$; (iv) $50 \% \mathrm{TFA}, \mathrm{CH}_{2} \mathrm{Cl}_{2}, 30 \mathrm{~min}, 33 \%$, v) $\mathrm{SnCl}_{2} \cdot 2 \mathrm{H}_{2} \mathrm{O}$, DIEA, NMP, r.t., 2 h.

\section{Scheme 19.}

Calver et $a l . .^{28}$ reported a high throughput synthesis of diverse 2,5-disubstituted indoles 143 using titanium carbenoids bearing boronate functionality (Scheme 20). Suzuki cross-coupling with aryl iodides followed by cleavage with acid completed the solid-phase synthesis of 2,5-disubstituted indoles.

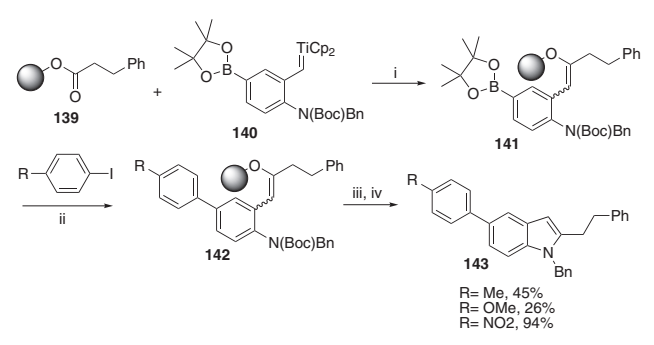

Reagents and conditions: i) THF; ii) $4 \mathrm{~mol} \% \mathrm{Pd}\left(\mathrm{PPh}_{3}\right)_{4}, 1$ eq. $\mathrm{H}_{2} \mathrm{O}, \mathrm{DMF}$, $80{ }^{\circ} \mathrm{C}$; iii) $1 \%$ TFA, $\mathrm{CH}_{2} \mathrm{Cl}_{2}$; iv) $10 \%$ TFA, $\mathrm{CH}_{2} \mathrm{Cl}_{2}$.

\section{Scheme 20.}

Recently, Larock et al. ${ }^{29}$ report the construction of a 42-member library of highly substituted indoles 149 and 150 by the solid-phase synthesis of 4-iodoindoles 147 and subsequent palladium-catalyzed Sonogashira and Suzuki-Miyaura cross-coupling reactions with various commercially available terminal alkynes and boronic acids (Scheme 21). The chemistry has been successfully performed in a solid support using chlorinated Wang resin and diversity has been achieved at the 5-position by different cleavage reactions. The average yield of the library was $46 \%$ and the average purity after purification was $94 \%$.

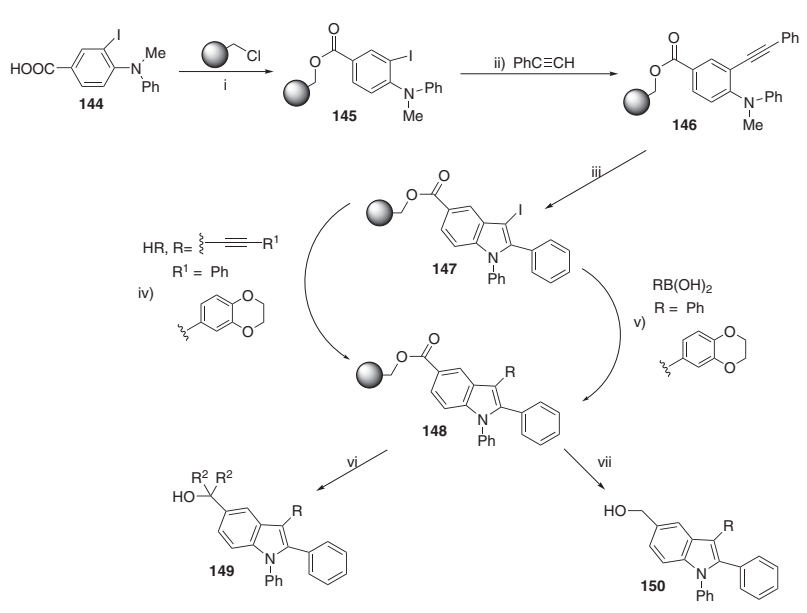

Reagents and conditions: i) $\mathrm{Cs}_{2} \mathrm{CO}_{3}, \mathrm{KI}, \mathrm{DMF}, 80 \%$; ii) $5 \mathrm{~mol} \%$ $\mathrm{PdCl}_{2}\left(\mathrm{PPh}_{3}\right)_{2}, 10 \mathrm{~mol} \% \mathrm{CuI}, \mathrm{HNEt}_{2}$, r.t.; iii) $3.0 \mathrm{I}_{2}, \mathrm{CH}_{2} \mathrm{Cl}_{2}, 24 \mathrm{~h}$; iv) $5 \mathrm{~mol} \%$ $\left.\mathrm{PdCl}_{2}\left(\mathrm{PPh}_{3}\right)_{2}, 10 \mathrm{~mol} \% \mathrm{CuI}, \mathrm{HNEt}_{2}, 48 \mathrm{~h}, 65^{\circ} \mathrm{C} ; \mathrm{v}\right)$ cat. $\mathrm{Pd}(\mathrm{OAc})_{2}, \mathrm{PPh}_{3}$, CsF, DME, 40 h, 80\%; vi) $\mathrm{R}_{2} \mathrm{MgBr}$, THF ( $\mathrm{R}_{2}=\mathrm{Me}$, Et); vii) $\mathrm{LiAlH}_{4}$, THF.

\section{Scheme 21.}

Hyacinthacine is a new set of alkaloids isolated from Hyacinthoides non-scripta and Scilla campanulata immature fruits and bluebell stalks which inhibit several glycosidase enzymes. A new solid-phase synthesis of pyrrolizidine nucleus related to hyacinthacine core using $L$-Boc-proline (152) as the building block was reported (Scheme 22) ${ }^{30}$ The synthesis with Merrifield resin $\mathbf{1 5 1}$ as solid support occurs only in four steps. The route includes an elegant cyclization cleavage strategy step, which releases product 157 from the resin in good yields under Baylis-Hillman conditions.

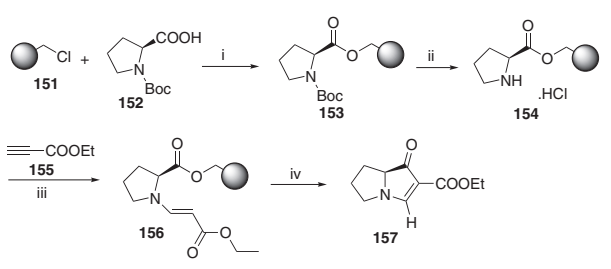

Reagents and conditions: i) $\mathrm{K}_{2} \mathrm{CO}_{3}$, KI, reflux, $24 \mathrm{~h}$; ii) $\mathrm{CH}_{2} \mathrm{Cl}_{2} / \mathrm{Et}_{2} \mathrm{O}$, $\mathrm{HCl} 3 \mathrm{~mol} \mathrm{~L}^{-1}$; iii) DIPEA, DMF, 4 days, r.t.; iv) 1,8-diazabicyclo[5.4.0] undec-7-ene (DBU), MW, $10 \mathrm{~min}$.

\section{Scheme 22.}

\section{Terpenes and Steroids}

Terpenoids, also referred to as terpenes, are the largest group of natural compounds (over 55,000 members isolated 
so far). From simple structures as menthol until complex ones as taxol, terpenes are a ubiquitous group of molecules that have long provided humans with flavours, fragrances, hormones, medicines and even commercial products such as rubber. ${ }^{31}$ They are often found in significant quantities, and a wide array isolated and characterized. Chemically, they are built from five-carbon isoprene units and so can also be called "isoprenoids". Molecules with multiples of 5 carbons and particularly with single carbon side chains belong to this group, even if they are cyclic. Based on the number of the building blocks, terpenoids are commonly classified as monoterpenes $\left(\mathrm{C}_{10}\right)$, sesquiterpenes $\left(\mathrm{C}_{15}\right)$, diterpenes $\left(\mathrm{C}_{20}\right)$, and sesterterpenes $\left(\mathrm{C}_{25}\right)$. More complex terpenoids include the sterols. Many terpenes have biological activities and are used for the treatment of human diseases, been active against cancer, malaria, inflammation, and a variety of infectious diseases. ${ }^{32}$ There are several methods described in literature to obtain these compounds by synthesis, however, they are not easily synthesized by solid-phase synthesis. The current literature revealed a few examples.

To input molecular diversity in hydroxysteroids (primary alcohol, secondary alcohols, and phenol), Maltais and co-workers ${ }^{33}$ utilized solid-phase reactions where hydroxysteroids were linked to solid support using the butyldiethylsilane polystyrene (PS-DES) resin. The synthesized compounds were made by running steroidal alcohols 158 and $\mathbf{1 5 9}$ through a model sequence of reactions: solid-phase coupling, aminolysis of oxirane or reduction of azide, amidation, and final cleavage, as seen in Schemes 23 and 24. The reaction led to good overall yields ( $>45 \%$ ) and high HPLC purities ( $>90 \%$ ) of hydroxysteroids derivatized as alkylamides (174) and alkylamines $(166,167,175)$ without purification.

Another steroid considered in the solid-phase combinatorial synthesis is estradiol and its derivatives that contain a functionalized side chain at positions $16 \beta$ or $7 \alpha .{ }^{34}$ Both types of derivatives have demonstrated inhibitory activity toward biosynthesis and action of estradiol. In $2000,{ }^{35}$ the same group enlarged the library of estradiol 16p-(azidopropyl) compounds $(\mathbf{1 7 7})^{34}$ with the synthesis of phenolic sterols derivatives. The authors used the same approach in which they generated two levels of diversity from two functional groups, where they introduced commercially available building blocks, such as amino acids, acyl chlorides, and anhydrides (Scheme 25).

Taxol (paclitaxel) is an antimicrotubule agent clinically available to treat ovarian, breast, lung cancer and also Kaposi sarcoma. ${ }^{36}$ Systematic SPOS and structure activity relationship (SAR) studies of taxol analogs were done by Nicolaou et al. ${ }^{37}$ They started with an appropriately functionalized taxol core (five steps from baccatin III, 181) that was attached onto 2-chlorotritylchloride polystyrene resin and the loaded resin is distributed into $400 \mathrm{Rf}$ tagged MicroKan reactors (Scheme 26). The reactors

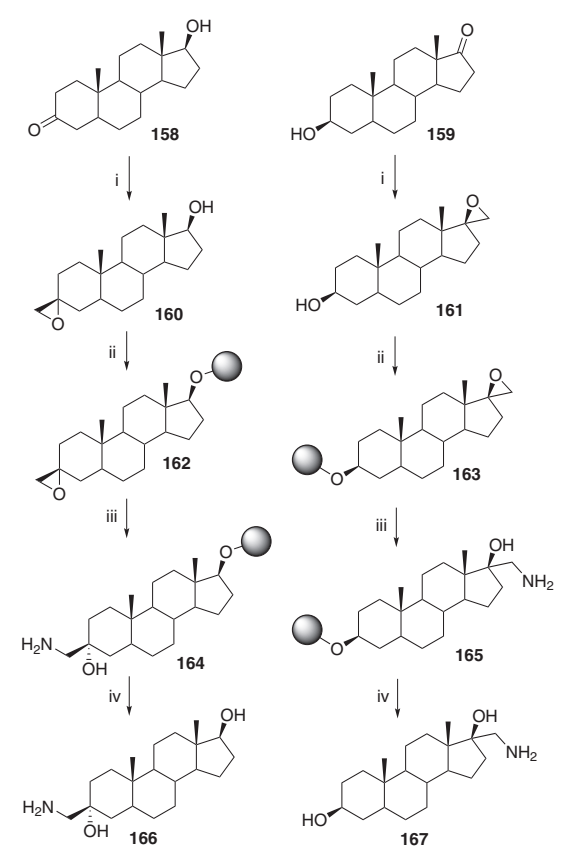

Reagents and conditions: i) $\mathrm{NaH},\left(\mathrm{CH}_{3}\right)_{3} \mathrm{SOI}$, DMSO, r.t.; ii) imidazole, polymer supported butyldiethylcholos (PS-DES-Cl) resin, $\mathrm{CH}_{2} \mathrm{Cl}_{2}$, r.t.; iii) Amine/EtOH (1:1), $60^{\circ} \mathrm{C}$; iv) HF-pyridine, THF, r.t.

Scheme 23.

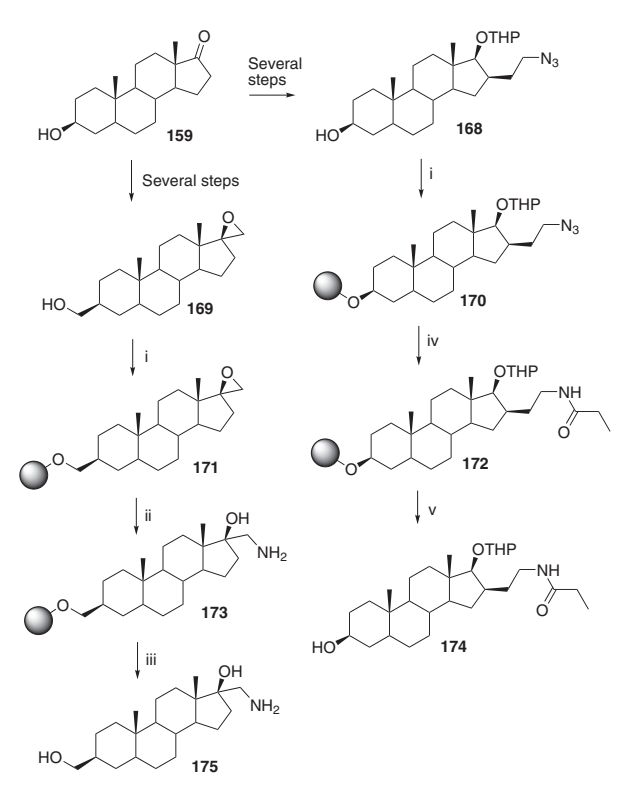

Reagents and conditions: i) imidazole, $\mathrm{PS}-\mathrm{DES}-\mathrm{Cl}$ resin, $\mathrm{CH}_{2} \mathrm{Cl}_{2}$, r.t.; ii) Amine/EtOH (1:1), $60{ }^{\circ} \mathrm{C}$; iii) HF-pyridine, THF, r.t..; iv) $\mathrm{SnCl}_{2}, \mathrm{Et}_{3} \mathrm{~N}$, $\mathrm{PhSH}$, THF, r.t.; v) TBAF, THF, r.t.

Scheme 24 . 


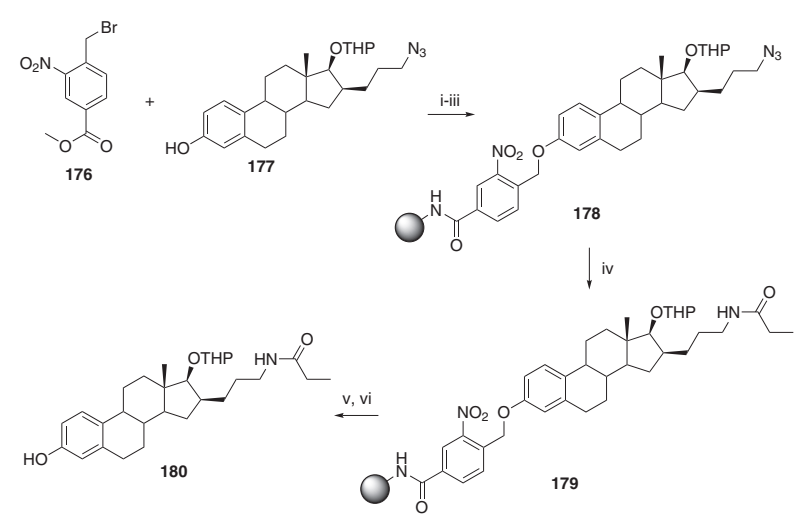

Reagents and conditions: i) $\mathrm{Cs}_{2} \mathrm{CO}_{3}, \mathrm{CH}_{3} \mathrm{CN} / \mathrm{DMF}$ (4:1), r.t. (67\%); ii) $\mathrm{LiOH}$ aq, THF, r.t. (83\%); iii) aminomethyl resin $\left(1.0 \mathrm{mmol} \mathrm{g} \mathrm{g}^{-1}\right)$, DIPC, HOBt, DMF, r.t.; iv) propionic acid, EDC, HOBt, dioxane, then $\mathrm{Bu}_{3} \mathrm{P}$ in toluene, r.t.; v) hv (350 nm), $\mathrm{MeOH}$, r.t.; vi) $2 \% \mathrm{HCl}, \mathrm{MeOH}$, r.t.

Scheme 25 .

were treated as one single batch with $5 \%$ piperidine/ $N, N^{\prime}$-dimethylformamide (DMF) (r.t., $30 \mathrm{~min}$ ) to deprotect the Fmoc group and, after that, the reactors were sorted into 20 groups that were acylated with a carboxylic acid to yield the resin-bound amides (182). The amides were divided again and each new group was acylated with a second carboxylic acid 1,3-diisopropylcarbodiimide(DIC)/ $N, N$ '-dimethylaminopyridine(DMAP)/ $\mathrm{CH}_{2} \mathrm{Cl}_{2}$ ) yielding the diesthers $(\mathbf{1 8 3})$ on resin. Finally the cleavage furnished a library of $400(20 \times 20)$ taxol analogs $(\mathbf{1 8 4})$.

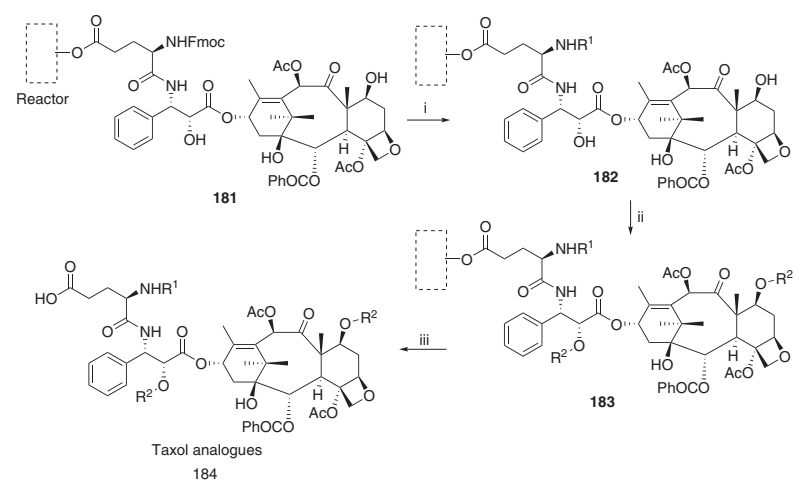

Reagents and conditions: i) 5\% piperidine, DMF, then carboxylic acids $\left(\mathrm{R}^{1}\right)$, benzotriazole-1-yl-oxy-tris-pyrrolidinophosphonium hexafluorophosphate (PyBOP), DIEA, DMF; ii) carboxylic acids $\left(\mathrm{R}^{2}\right)$; iii) $\mathrm{AcOH}, \mathrm{CF}_{3} \mathrm{CH}_{2} \mathrm{OH}, \mathrm{CH}_{2} \mathrm{Cl}_{2}$.

\section{Scheme 26.}

Secosteroids, as vitamin $\mathrm{D}$, are steroids in which one of the bonds in the rings is broken. Vitamin D is obtained by SPOS through different approaches. In 2001, Hojikuro and Takahashi ${ }^{38}$ proposed a route where synthetic analogs of vitamin D were prepared by using a solid-supported CD-ring 186 (Scheme 27). The vitamin D3 system (188) was synthesized by Horner-Wadsworth-Emmons (HWE) reaction of the A-ring phosphine oxide $\mathbf{1 8 5}$ to resin 186, followed by introduction of the side chain and cleavage from resin.

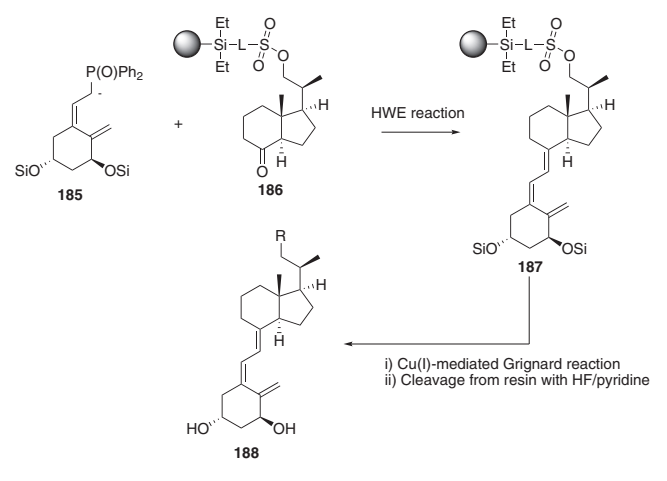

Scheme 27.

Squalamine 189 (Figure 1) is a water-soluble antibiotic, which exhibits potent bactericidal activity against both Gram-negative and Gram-positive bacteria, is fungicidal and induces osmotic lysis of protozoa. ${ }^{39}$ Squalamine was used as template in solid-phase synthesis to produce analogues ${ }^{40}$ The chosen linker was suitable for cleaving directly within a biological assay. This approach was based on the 1,6-elimination process that uses an in-built amine 'activator' ( $\mathrm{N}$ from NHBoc in 191) to cleave a phenoxy ester (191a and 191b) and hence to activate the linker without giving rise to free quinone methide by-products 193 , as seen in Scheme 28. The utilization of this linker could be useful to accelerate the screening processes of libraries prepared by SPOS.

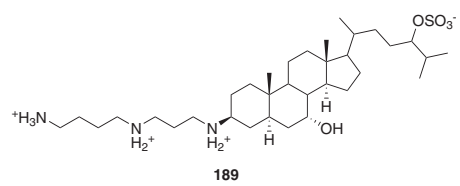

Figure 1. Chemical structure of squalamine 189.

To produce a library of des-C,D derivatives of 19-nor1 $\alpha, 25$-dihydroxyvitamin D3, Hanazawa and colleagues developed a general methodology disclosed in Scheme 29. ${ }^{41}$ After the A ring 195 been attached to the resin, the product was coupled with 196 to give 197 and then treated with an excess amount of $\mathrm{MeMgCl}$ or EtMgBr and then aqueous $\mathrm{HF}$ to produce the new des-C,D-19-nor-vitamin D3 derivatives, such as $\mathbf{1 9 8}$.

Jagtap $^{42}$ and co-workers used as alternative solidsupport a polystyrene-divinyl benzene resin functionalized with a PE-DES-Cl to obtain a series of 10-acyl (203) and 7,10-diacyl (202) paclitaxel analogues (Scheme 30). The starting material was 10-deacetylpaclitaxel $\mathbf{1 9 8}$ that 


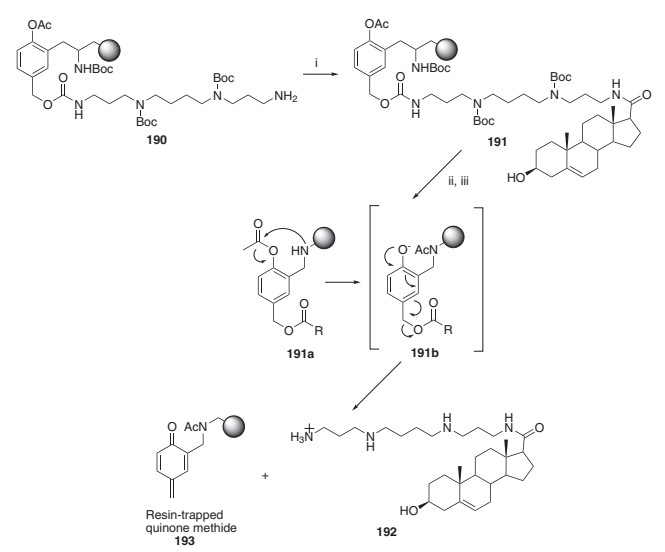

Reagents and contitions: i) $\beta$-acetoxybisnor-5-chlolenic acid/DIC/HOBt; ii) $\mathrm{Py} \cdot \mathrm{SO}_{3}, \mathrm{CHCl}_{3}$; iii) $50 \% \mathrm{TFA}$ in dichloromethane (DCM) $1 \mathrm{~h}$, then phosphate buffer ( $\mathrm{pH} 8.0), 24 \mathrm{~h}$.

Scheme 28.

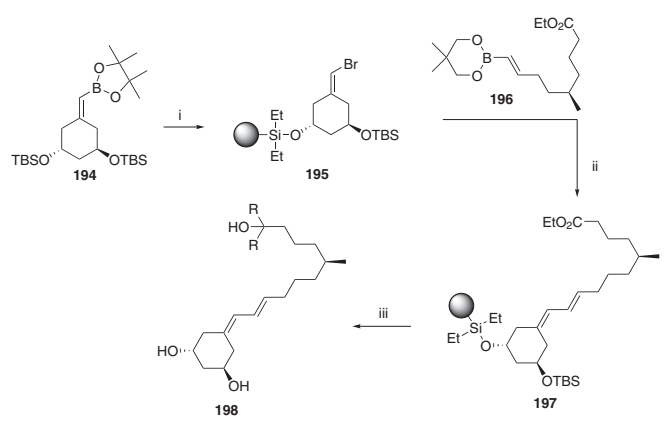

Reagents and conditions: i) PS-DES-Cl, imidazole, DCM; ii) $\mathrm{PdCl}_{2}$ catalyst, $\mathrm{KOH}$, THF, $\mathrm{H}_{2} \mathrm{O}$; iii) $\mathrm{MeMgCl}$ or $\mathrm{EtMgBr}$, THF, then aqueous HF, THF.

Scheme 29.

was bonded into resin 199 to give and then converted to the correspondent 10-acyl analogues 200 by Holton's method. Subsequent acylation at the C-7 position was performed using different carboxylic acid and the acyl and diacyl libraries were delivered from the resin under acidic condition.

The sesquiterpenoid dysidiolide (204) (Figure 2) is an inhibitor of the dual-specificity $\mathrm{Cdc} 25$ protein phosphatase family that acts in the regulation of the cell cycle, isolated from the Caribbean sponge Dysidia etheria, Laubenfels. ${ }^{43}$ The solid-phase synthesis was employed to obtain dysidiolide analogues with overall yields ranging from $6 \%$ to $27 \% .{ }^{44}$ The eleven step transformation includes a variety of diverse reaction types widely used in organic synthesis like an asymmetric cycloaddition employing a removable chiral auxiliary, organometallic transformations, olefination reactions, oxidation reactions, acidic hydrolyses, and nucleophilic substitution.

Lupeol (205) is a triterpene found in fruits and vegetable and recently it was discovered that it is capable to inhibit

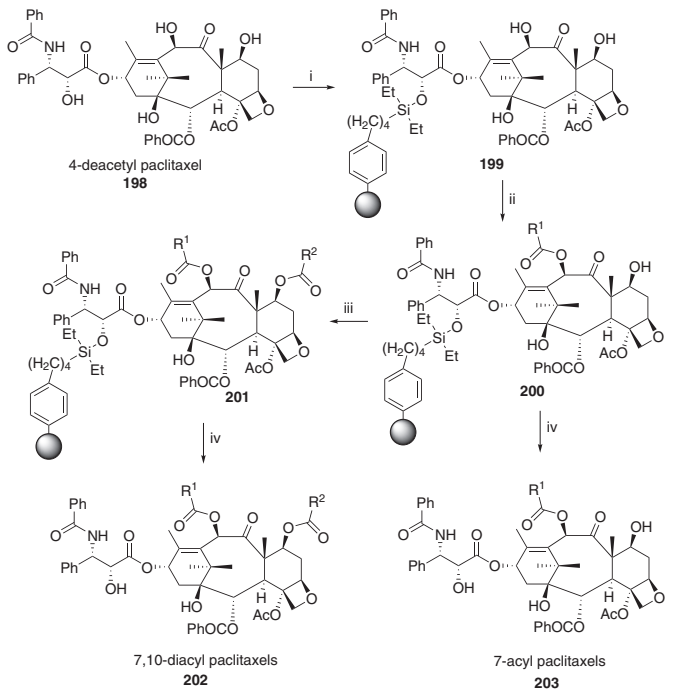

Reagents and conditions: i) resin, imidazole, $\mathrm{CH}_{2} \mathrm{Cl}_{2}$; ii) $\mathrm{R}_{1} \mathrm{COOCOR}$, $\mathrm{CeCl}_{3}$, THF; iii) $\mathrm{R}_{2} \mathrm{COOH}$, DIPC, Toluene; iv) Pyridine, HF, THF, then $\mathrm{MeOSiMe}_{3}$.

Scheme 30.

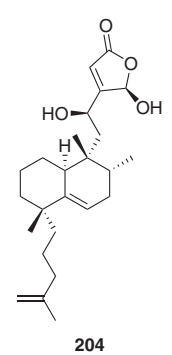

Figure 2. Chemical structure of dysidiolide.

tumors growth ${ }^{45}$ to act as anti-inflammatory, ${ }^{46}$ urolithic and anticalciuric and also express antimalarial activity against chloroquine-resistant Plasmodium falciparum. ${ }^{47}$ The use of lupeol as a scaffold for the synthesis of a library was described by Srinivasan (Scheme 31) ${ }^{48}$ The synthesis starts with lupeol 205 been attached to a Rink amide and Sieber amide solid resin, through aliphatic dicarboxylic acid moieties. These sites also served as point to introduce chemical diversity. The resulting polymer linked $3 \beta-O$ (resin-alkanoyl)-lup-20(29)-ene 206 was used to obtained intermediates $3 \beta-O$ (resin-alkanoyl)-30-bromo-lup-20(29)ene 207 and 33-O (resin-alkanoyl)-30-amino-lup-20(29)ene 208. The intermediates were used to prepared several derivatives (209-213).

The triterpenoids betulinic acid (214) and ursolic acid (217) were investigated as scaffolds for the generation of combinatorial libraries in parallel format using solid-phase organic synthesis. ${ }^{49}$ Both compounds have the potential for the synthesis and presenting two-point of structural diversity at C-3 and C-28 positions. The synthesis consisted in inmobilization of $\mathbf{2 1 4}$ or $\mathbf{2 1 7}$ to pre-derivatized amino 

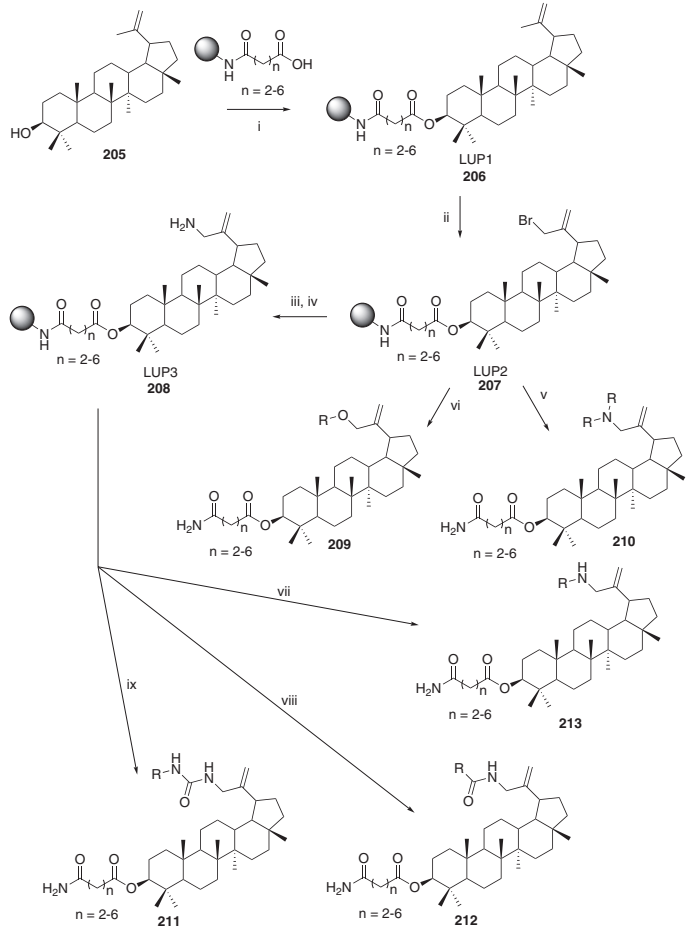

Reagents and conditions: i) DIC, DMAP, DMF/THF (1:1); ii) $N$-bromosuccinimide (NBS), $\mathrm{CH}_{2} \mathrm{Cl}_{2}: \mathrm{CCl}_{4}(1: 1), 6 \mathrm{~h}$; iii) $\mathrm{NaN}_{3}$, DMSO, $80{ }^{\circ} \mathrm{C}, 24 \mathrm{~h}$; iv) $\mathrm{SnCl}_{2}, \mathrm{PhSH}, \mathrm{Et}_{3} \mathrm{~N}$, THF, $2 \mathrm{~h}$; v) primary or secondary amine, DBU, $16 \mathrm{~h} / 1 \%$ TFA- $\mathrm{CH}_{2} \mathrm{Cl}_{2}, 10 \mathrm{~min}$; vi) Benzyl alcohol derivatives, DBU, $16 \mathrm{~h} / 1 \% \mathrm{TFA}-\mathrm{CH}_{2} \mathrm{Cl}_{2}, 10 \mathrm{~min}$; vii) $\mathrm{R}_{3} \mathrm{CHO}$, trimethyl orthoformate (TMOF)/DMF (2:1), $2 \mathrm{~h}$ then $\mathrm{NaCNBH}_{3}, 1 \%$ $\mathrm{AcOH}$ in TMO, $1 \mathrm{~h} / 1 \%$ TFA- $\mathrm{CH}_{2} \mathrm{Cl}_{2}, 10 \mathrm{~min}$; viii) $\mathrm{R}_{4} \mathrm{COOH}$, HOBt, DIC, DMF, $6 \mathrm{~h} / 1 \%$ TFA- $\mathrm{CH}_{2} \mathrm{Cl}_{2}, 10 \mathrm{~min}$; ix) $\mathrm{R}_{5} \mathrm{NCO}, \mathrm{CH}_{2} \mathrm{Cl}_{2}, 24 \mathrm{~h} / 1 \%$ TFA- $\mathrm{CH}_{2} \mathrm{Cl}_{2}, 10 \mathrm{~min}$.

\section{Scheme 31 .}

acid 2-chlorotrityl or Sieber amide resins, and then treated with a variety of aliphatic, aromatic and amino acids (Scheme 32).

In 2003, Ciabanou and Poirier $^{50}$ reported an application of the detachable sulfamate linker in the synthesis of libraries of $N$-derivatized $17 \alpha$-piperazinomethyl estradiols (phenols and sulfamates) by solid-phase parallel
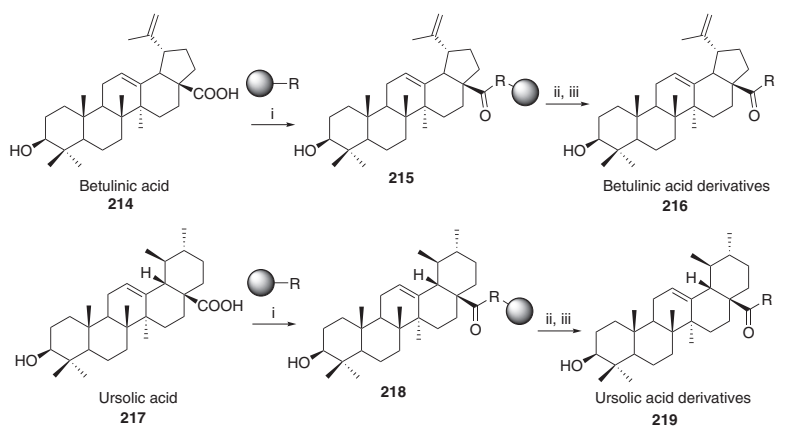

Reagents and conditions: i) pyridinium dichromate (PDC)/DMF; ii) $\mathrm{RCOOH} / \mathrm{DMA} / \mathrm{DIC}$; iii) $\mathrm{TFA} / \mathrm{CH}_{2} \mathrm{Cl}_{2}$.

Scheme 32. chemistry. The starting material was a 3-sulfamoyl-17 $\alpha$ ( $N$-trifluoroacetyl-piperazinomethyl) estradiol 221, that was prepared in solution from estrone $\mathbf{2 2 0}$ and loaded efficiently onto trityl chloride resin (Scheme 33). After cleavage of the trifluoroacetyl protecting group, sequential acylation reactions with five Fmoc-protected amino acids and five carboxylic acids were performed to introduce two levels of molecular diversity. The final step with the resin split and the delivery of the products occurred using two protocols: under acidic conditions with $5 \%$ trifluoroacetic acid in dichloromethane, and by nucleophilic attack with piperazine in tetrahydrofuran.

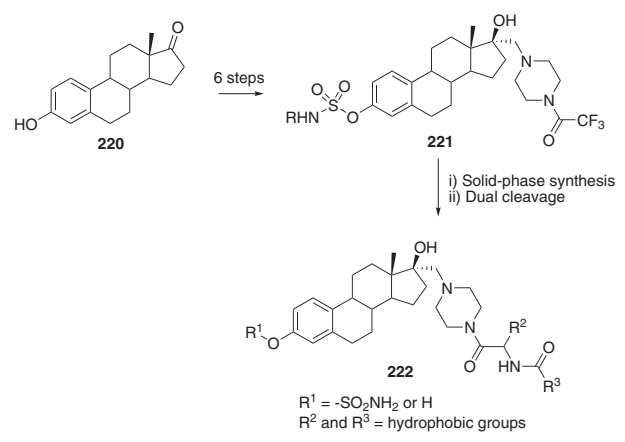

Scheme 33.

Analogues of geraniol, a monoterpene found in essential oils of fruits and herbs, have been studied by Subramanian and co-workers. ${ }^{51}$ They published the solid-phase synthesis of a library of 80 anilinogeranyl alcohols $\mathbf{2 2 7}$ and diphosphates $\mathbf{2 2 8}$ in three steps: reductive amination, bromination, and treatment with $\left((n-\mathrm{Bu})_{4} \mathrm{~N}_{3} \mathrm{HP}_{2} \mathrm{O}_{7}\right.$ [tris (tetra- $N$-butylammonium)hydrogendiphosphate]. The SPOS started with the attachment of synthetic intermediates to the tetrahydropyranyl (THP) resin $\mathbf{2 2 3}$ (prepared from the Merrifield resin), combining a five-fold excess of 8-oxo-geraniaol 224 with the polymeric support in the presence of 0.2 equiv. of PPTS at $60{ }^{\circ} \mathrm{C}$ (Scheme 34). Anilinogeraniols attached to the resin $\mathbf{2 2 6}$ were obtained by reductive amination of $\mathbf{2 2 5}$ with 10 equiv. of the anilines and 12 equiv. of acetic acid in 1:1 THF/N,N'dicyclohexylcarbodiimide (DCE) and subsequent reduction with 10 equiv. of $\mathrm{NaBH}(\mathrm{OAc})_{3}$. The cleavage step of $\mathbf{2 2 7}$ was done by treatment of the solid support with DCE/ $\mathrm{MeOH} /$ pyridinium p-toluenesulfonate (PPTS) at $60^{\circ} \mathrm{C}$. To obtain the diphosphates $\mathbf{2 2 8}$, compound $\mathbf{2 2 6}$ reacted with 3 equiv. of $\mathrm{Ph}_{3} \mathrm{PBr}_{2}$ in $\mathrm{CH}_{2} \mathrm{Cl}_{2}$ for $4 \mathrm{~h}$ followed by addition of 10 equiv. of $\left[(n-\mathrm{Bu})_{4} \mathrm{~N}_{3} \mathrm{HP}_{2} \mathrm{O}_{7}\right.$ in $\mathrm{CH}_{3} \mathrm{CN}$, furnishing the desired diphosphates in moderate yield.

Another steroid synthesized by SPOS was a new type of cyclic peptidosteroid $\mathbf{2 3 5}$, in which a bile-acid-based scaffold was used for the conformational restriction of 


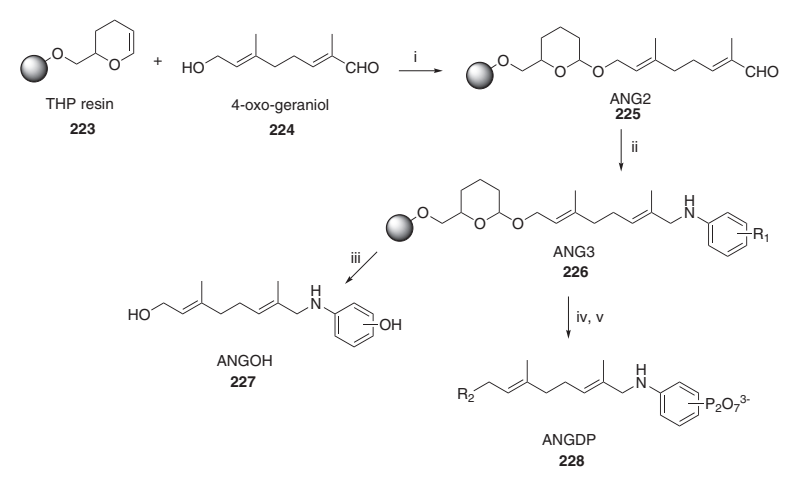

Reagents and contitions: i) PPTS, DCE, $60^{\circ} \mathrm{C}, 78 \%$; ii) Aniline, $\mathrm{AcOH}$, $\mathrm{NaBH}(\mathrm{OAc})_{3}$, THF/DCE (1:1), r.t.; iii) PPTS, $\mathrm{CH}_{3} \mathrm{OH} / \mathrm{DCE}(1: 1), 60^{\circ} \mathrm{C}$, $24-90 \%$; iv) $\left((n-\mathrm{Bu})_{4} \mathrm{~N}\right)_{3} \mathrm{HP}_{2} \mathrm{O}_{7}, \mathrm{CH}_{3} \mathrm{CN}$, r.t. v) $\mathrm{DCE} / \mathrm{MeOH} / \mathrm{PPTS}$ at $60^{\circ} \mathrm{C}$.

Scheme 34.

a loop-like peptide.$^{52}$ The coupling of two tetrapeptides to the non-peptidic bili-acid scaffold $\mathbf{2 3 0}$ was carried out once in the classical C-to-N peptide synthesis and once in the non-classical N-to-C direction. Peptide backbone cyclization was then carried out, giving rise to a ring size equivalent to approximately 12 amino acids (Scheme 35 ).

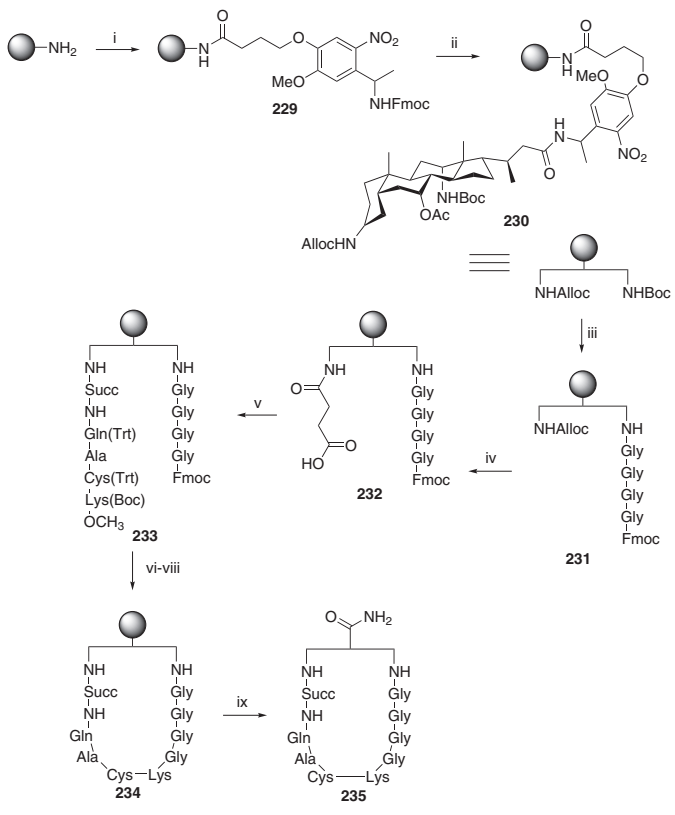

Reagents and conditions: i) 4-\{4-[1-(9-fluorenylmethoxycarbonylamino) ethyl]-2-methoxy-5-nitrophenoxy \} butanoic acid, PyBOP, DIPEA, DMF, $2 \mathrm{~h}$, r.t.; ii) $20 \%$ piperidine/DMF, $2 \times 20 \mathrm{~min}$, r.t., then, methyl 7 - $\alpha$-acetoxy$3 \alpha$-[N-(allyloxycarbonyl)amino]-12 $\alpha$-[N-( $t$-butyloxycarbonyl)amino]$5 \beta$-cholan-24-oate ,PyBOP, DIPEA, DMF, 2 h, r.t. iii) $20 \%$ TFA, $\mathrm{CH}_{2} \mathrm{Cl}_{2}$, $20+90$ min, r.t. then, Fmoc-Gly4-OH, HOAt, DIC, DMF, r.t.; iv) $\mathrm{Pd}\left(\mathrm{PPh}_{3}\right)_{4}$, $\mathrm{Bu}_{3} \mathrm{SnH}$, succinic anhydride, $\mathrm{CH}_{2} \mathrm{Cl}_{2}, 2 \times 17$ h, r.t.; v) H-Gln(Trt)-AlaCys(Trt)-Lys(Boc)-OMe, HATU, TMP, DMF, r.t.; vi) LiOH 0.33M, $\mathrm{MeOH} / \mathrm{H}_{2} \mathrm{O}, 4$ d, r.t.; vii) 1-hydroxy-7-azabenzotriazole (HOBt), TBTU, DIPEA, DMF, r.t.; viii) TFA/ $\mathrm{H}_{2} \mathrm{O} /$ triisopropylsilane (TIS), 2 h, r.t.; ix) hv (365 nm), 1\% DMSO/dioxane, $4 \times 4$ h, r.t.

Scheme 35 .
Solanesol $\mathbf{2 4 0}$ is a terpene isolated from tobacco and it is an important intermediate of nutrients such as vitamin $\mathrm{K} 2$ and coenzyme Q10. Besides the efforts to obtain it by solution-phase synthesis, which require expensive chromatographic purification, Yu et al. ${ }^{53}$ described a solid-phase synthetic strategy of solanesol. The SPOS route started from commercially available geraniol $\mathbf{2 3 7}$ and provided the facile isolation of product from the support-bounded intermediate in 50\% of overall yield. In the proposed route, a dihydropyran-modified resin (236) is coupled to Merrifield resin and after some steps a polymersupported bromide $\mathbf{2 3 8}$ is prepared (Scheme 36). This bromide reacted to give polymer-support nonamer 239. Finally, treatment with PPTS was performed and completes the total solid-phase synthesis of solanesol $\mathbf{2 4 0}$.

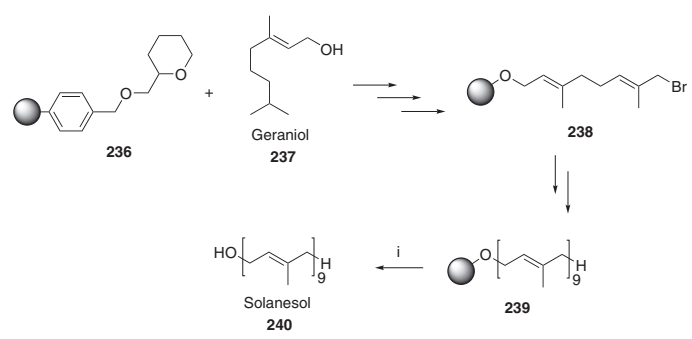

Reagents and conditions: (i) PPTS, 1:1 n-butanol/1,2 dichloroethane, $80{ }^{\circ} \mathrm{C}, 16 \mathrm{~h}$.

Scheme 36 .

The triterpene maslinic acid $\mathbf{2 4 3}$ is an oleanane isolated from olive oil which has been identified as antiproliferative agent of colon cancer cells ${ }^{54}$ and antiHIV. ${ }^{55}$ The construction of a library with the maslinic acid as a scaffold was presented in $2009,{ }^{55}$ where the acid was coupled at C-28 with several amino acids using solid-phase reactions to prepare a dipeptide, a tripeptide, and a series of conjugate dipeptides. Due to the high hydrophobicity of maslinic acis, it is very suitable to be utilized in solid-phase. The strategy consisted on the coupling of one, two, or three amino acid fragments with the carboxyl group at C-28 of maslinic acid. The pathway employed for the synthesis of one dipeptide derivative is described in Scheme 37.

Recently, Nicolletti et al..$^{56}$ described the synthesis of 25-hydroxylated vitamin D3 analogues by a five-step route using a (hydroxymethyl)polystyrene support (Scheme 38). The CD-side chain fragment was anchored to the solid support through an ester group at C25 (245) and coupled to the A ring of building block 246 to assemble the vitamin D triene system 247 by Wittig-Horner reaction. Prior to functionalization at $\mathrm{C} 25$ of $\mathbf{2 4 8}$, the hydroxy group was deprotected and the cleavage was done by nucleophilic attack on the ester carbonyl group. 


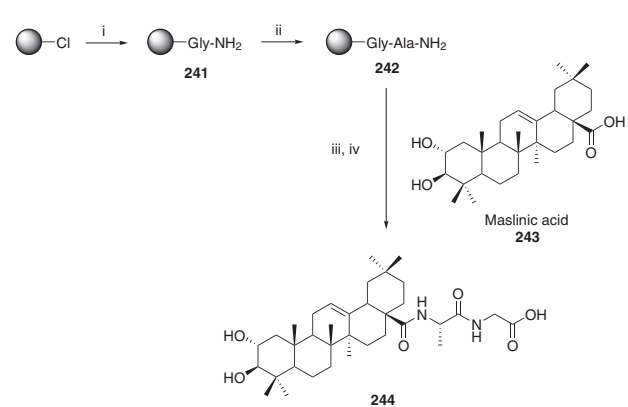

Reagents and conditions: i) Fmoc-Gly-OH, N,N-diisopropylethylamine (DIEA), $\mathrm{CH}_{2} \mathrm{Cl}_{2} /$ Piperidine-DMF; ii) Fmoc-Ala-OH, N-hydroxybenzotriazole (HOBt), N,N-diisopropylcarbodiimide (DIPCDI), $\mathrm{CH}_{2} \mathrm{Cl}_{2} /$ Piperidine-DMF; iii) Maslinic acid, 7-azabenzotriazol1-yloxytris (pyrrolidino) phosphonium hexafluorophosphate (PyAOP), 1-hydroxy-7-azabenzotriazole (HOAt), DIEA, DMF; iv) TFA, $\mathrm{CH}_{2} \mathrm{Cl}_{2}$.

Scheme 37.

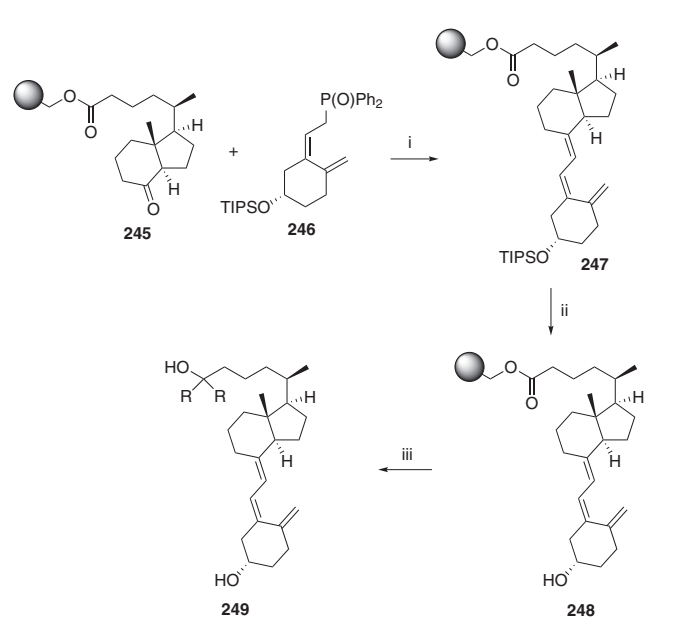

Reagents and conditions: i) n-BuLi, THF; ii) HF, $\mathrm{Py}, \mathrm{CH}_{2} \mathrm{Cl}_{2}$, Acetonitrile; iii) MeLi, THF.

Scheme 38.

\section{Coumarins}

Coumarins are structurally related to lactones from $o$-cinamic acid, where the 1,2-benzopyrone is the simplest representative. The most investigated in medicinal chemistry is the use of furanecoumarins, which possesses some biological properties like vasodilator and bronchodilator. Because of this, the synthesis of coumarins by combinatorial chemistry has gained some interest including the synthesis of coumarins by SPOS or its use as scaffold to prepare combinatorial libraries of coumarins derivatives.

The design of a reliable synthetic route for the solidphase method for parallel synthesis of 2,3-disubstituted 6H-pyrano[2,3-f]benzimidazole-6-ones (2,3-disubstituted imidazocoumarins) has been achieved. ${ }^{57}$ This strategy, which is based on the mild imidazole ring closure reaction, provides a 2,3-disubstituted imidazocoumarin library 256 with two sites of chemical diversity for anticancer drug investigations (Scheme 40). The synthesis started with coupling of Rink amide resin MBHA with 7-fluoro-4methyl-6-nitro-coumarin-3-carbocylic acid 250, after which furnished 26 tricyclic compounds in six steps with high purity and good yields. The synthesis employs available building blocks and the reactions were carried out under ambient conditions.

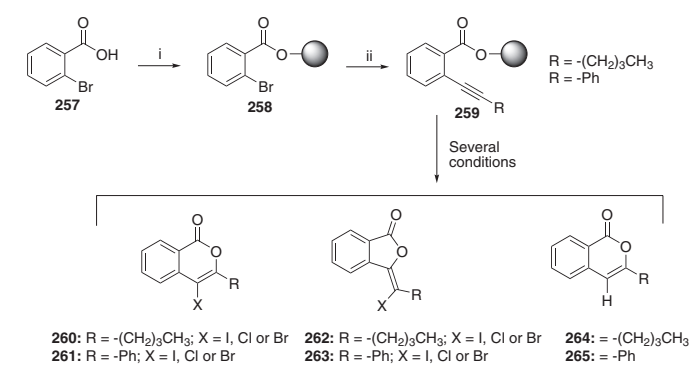

Reagents and conditions: i) 7-fluoro-4-methyl-6-nitro-coumarin-3carboxylic acid, DIC, $\mathrm{HOBt}$, DMF, 16 h, r.t.; ii) $\mathrm{R}^{1} \mathrm{NH}_{2}$ in 5\% DIPEA/ DMF, overnight, r.t.; iii) $\mathrm{SnCl}_{2} 1 \mathrm{M}$ in DMF, 24 h, r.t.; iv) $\mathrm{R}^{2} \mathrm{CHO}$, DMF, r.t. 2 h; v) 2,3-dichloro-5,6-dicyanobenzoquinone (DDQ), DMF, 5 h, r.t.; vi) $\mathrm{TFA} / \mathrm{H}_{2} \mathrm{O}, 2$ h, r.t.

\section{Scheme 39.}

In order to develop a synthetic approach to gain both efficiency and diversity around the isocoumarin scaffold, it was recently established a parallel solid-phase synthesis method for the production of 3-substituted 4-haloisocoumarins based on an electrophile-promoted halocyclization of supported 2-(alk-1-ynyl)benzoates (Scheme 39$).{ }^{58}$ The authors employed two-step strategy involving $(i)$ a Sonogashira cross-coupling reaction between polymer-bound 2-bromobenzoates $\mathbf{2 5 8}$ and terminal alkynes, followed by (ii) an electrophileinduced halocyclization of the resulting 2-(alk-1-ynyl) benzoates 259 through activation of the triple bond with the subsequent release of the isocoumarins. This synthesis allowed large variations at positions 3 and 4 of the isocoumarin scaffold and on the aromatic moiety. Using this strategy they built a library of 58 isocoumarins with high purities ( $82 \%$ of compounds with purity above $80 \%$ ) and the yields for the key reactions (Sonogashira cross-coupling and electrocyclization) were moderate to excellent ( $30 \%$ to quantitative). In addition, the authors could recycle the resin and apply one of well-known advantage of the solid support, which is the temporary protection of one functional group (i.e., the carboxylic group). In fact, the traceless cleavage would ensure that only the desired cyclized product is released from the polymer, with no cleavage of side products arising from an incomplete Sonogashira reaction. 


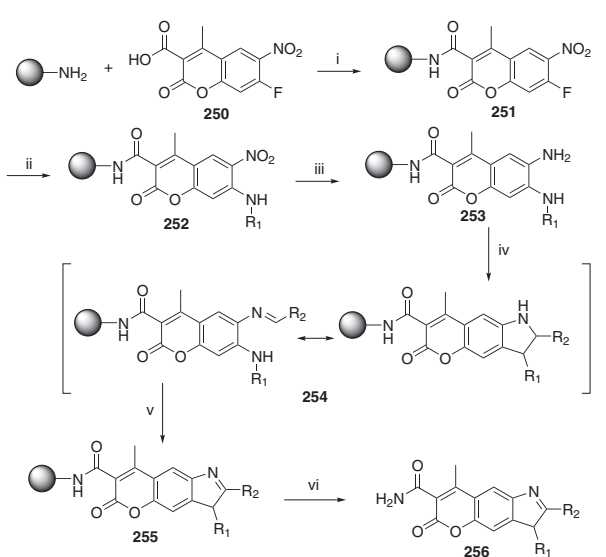

Reagents and conditions: i) $\mathrm{Cs}_{2} \mathrm{CO}_{3}$, EtOH, 3 h, r.t., then bromoWang resin, DMF, 12 h, r.t.; ii) alkyne (hex-1-yne or phenylacylene), $\mathrm{PdCl}_{2}\left(\mathrm{PPh}_{3}\right)_{2}, \mathrm{CuI}, \mathrm{Et}_{3} \mathrm{~N} / \mathrm{CH}_{2} \mathrm{Cl}_{2}, 65^{\circ} \mathrm{C}, 12 \mathrm{~h}$.

Scheme 40.

\section{Flavonoids}

The benzopyranone-ring system found in flavonoids is a molecular scaffold of considerable interest. Medicinal chemistry efforts have focused on diversifying benzopyranones and utilizing combinatorial chemistry approaches to construct small libraries in order to be evaluated, for example as potential enzyme inhibitors. ${ }^{59}$ Classically, 2,3-disubstituted benzopyranones $\mathbf{2 6 6}$ are synthesized by intramolecular condensation of compound 267, which is usually obtained by Baker-Venkataraman rearrangement of compound $\mathbf{2 6 8}$ or via Claisen ester condensation (Scheme 41). Previous reviews have discussed the importance of combinatorial libraries of flavonoids prepared by solid-phase synthesis. ${ }^{60}$

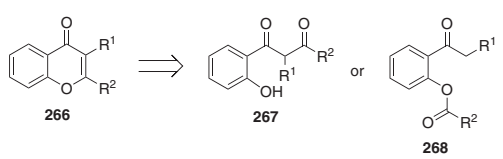

Scheme 41.

Harikrishnan and Showalter ${ }^{61}$ prepared a small library of isoflavone analogs employing a solid-supported diisopropylsilyloxy traceless linker. The key steps were the addition of Grignard reagents to salicyl aldehyde derivatives $\mathbf{2 7 2}$ and the cyclization employing amide acetals which introduced the $\mathrm{R}^{2}$ substituents on the isoflavones 275 (Scheme 42).

Bhat et al. ${ }^{62}$ employed a piperazinyl Merrifield resin in the synthesis of a library of flavones. The synthetic strategy involved the one pot conversion of bis-silylated salicylic acids 277 into alkynyl ketones 278 via an acid chlorination and subsequent Sonogashira coupling with

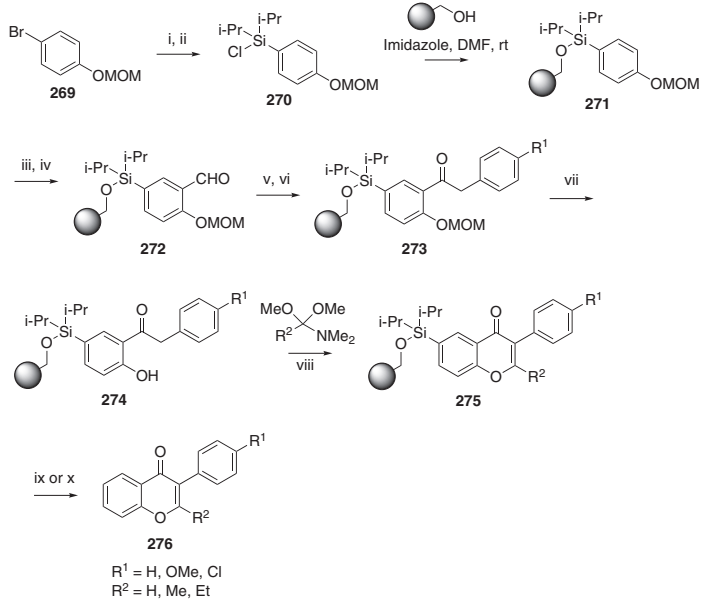

Conditions: i) $n$-BuLi, THF, $-78{ }^{\circ} \mathrm{C}$; ii) $(i \text {-Pr) })_{2} \mathrm{SiCl}_{2}$, THF, $-78{ }^{\circ} \mathrm{C}$ to r.t.; iii) $n$-BuLi, $N, N, N^{\prime}, N^{\prime}$-tetramethylenethylenediamine (TMEDA), $\mathrm{Et}_{2} \mathrm{O}, 0$ ${ }^{\circ} \mathrm{C}$; iv) DMF, $0^{\circ} \mathrm{C}$; v) 4- $\mathrm{R}^{1}-\mathrm{C}_{6} \mathrm{H}_{4} \mathrm{CH}_{2} \mathrm{MgCl}$, THF, $4 \mathrm{~h}$; vi) 2-iodoxybenzoic acid (IBX), DMSO/THF; vii) $4 \%$ THF, $\mathrm{CH}_{2} \mathrm{Cl}_{2}, 0{ }^{\circ} \mathrm{C}$; viii) THF, $40{ }^{\circ} \mathrm{C}$, $6 \mathrm{~h}$; ix) sat. CsF, DMF, $60{ }^{\circ} \mathrm{C}, 16 \mathrm{~h}$; x) 0.2 eq. TBAF, THF/DMF (1:4), $45^{\circ} \mathrm{C}, 30 \mathrm{~min}$.

\section{Scheme 42 .}

terminal alkynes. The alkynyl ketones $\mathbf{2 7 8}$ were treated with the secondary amine to form enaminones 279, which underwent a facile cyclization and elimination of secondary amine to provide the benzopyrone nucleus $\mathbf{2 8 0}$ (Scheme 43).

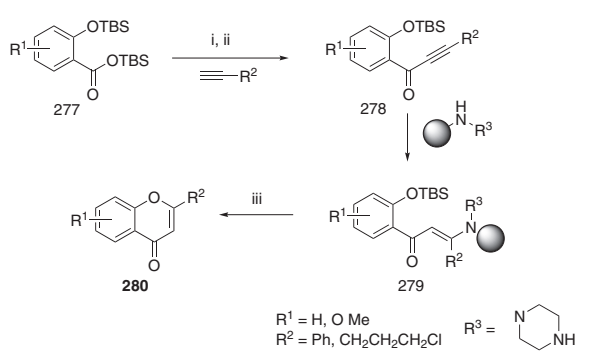

Reagents and conditions: i) $(\mathrm{COCl})_{2}, \mathrm{DMF}$; ii) $\mathrm{CuI}, \mathrm{Pd}\left(\mathrm{PPh}_{3}\right)_{2} \mathrm{Cl}_{2}, \mathrm{Et}_{3} \mathrm{~N}$; iii) $\mathrm{MeOH}$, reflux.

\section{Scheme 43.}

Nicolaou et al. ${ }^{63}$ reported a solid-phase synthesis of a 2,2-dimethylbenzopyran motif employing a cycloloading strategy that relies on the use of a polystyrene-based selenenyl bromide resin. In one natural product based library, a chalcone family of compounds was synthesized in parallel approach by condensing a variety of 11 aldehydes to a set of three resin-bound benzopyrans $\mathbf{2 8 2}$ containing a methyl ketone substituent (Scheme 44). Spontaneous dehydration of the resulting $\beta$-hydroxy ketone led to the supported chalcone $\mathbf{2 8 3}$ which was cleaved from the resin by hydrogen peroxide promoted selenoxide elimination to give the final product $\mathbf{2 8 4}$. On the other hand, treatment of supported chalcones $\mathbf{2 8 3}$ 
with iodine, followed by oxidative elimination, furnished flavones $\mathbf{2 8 6}$.

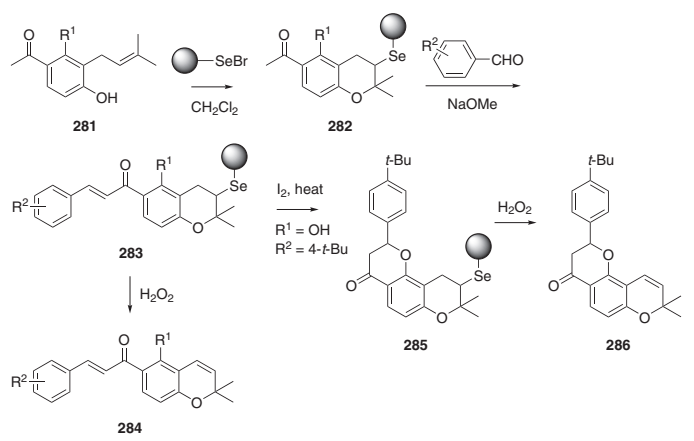

Scheme 44 .

Cheng et al.$^{64}$ prepared a small library of 12 chalcones via parallel solid phase synthesis. The immobilized hydroxyacetophenones $\mathbf{2 8 8}$ were submitted to a ClaisenSchmidt condensation with a series of arylaldehydes resulting in the chalcones $\mathbf{2 9 0}$ which were then cleaved from the resin yielding chalcones 291 (Scheme 45).

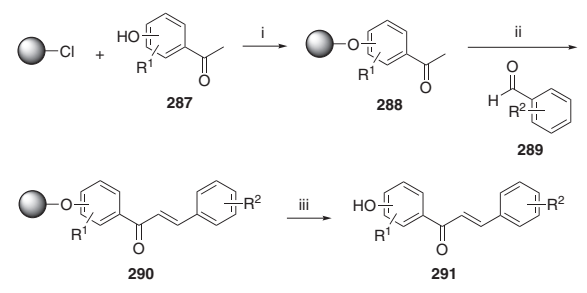

Reagents and conditions: i) pyridine, $\mathrm{CH}_{2} \mathrm{Cl}_{2}$; ii) $\mathrm{NaOH}, \mathrm{MeOH}$, DMF; iii) TFA, $\mathrm{CH}_{2} \mathrm{Cl}_{2}$.

\section{Scheme 45 .}

Huang et al.$^{65}$ described a solid-phase synthesis of flavones employing a Lewis acid-mediated polystyrenesupported selenium which induced intramolecular cyclization of chalcones 292. After the oxidative cleavage of selenium resin, the flavones $\mathbf{2 9 4}$ were obtained in good overall yields and high purity (Scheme 46 ).

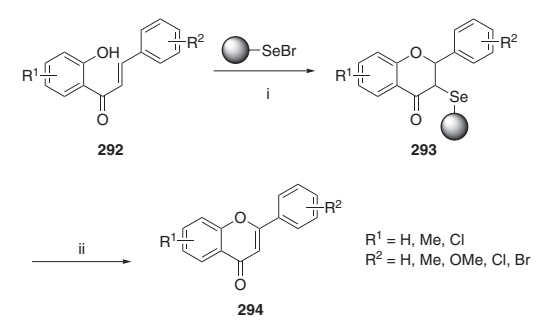

Reagents and conditions: i) $\mathrm{ZnCl}_{2}, \mathrm{CH}_{2} \mathrm{Cl}_{2}$, r.t., $12 \mathrm{~h}$; ii) $\mathrm{H}_{2} \mathrm{O}_{2}$, THF, $0{ }^{\circ} \mathrm{C}$ to r.t.

Scheme 46.
A different strategy was employed by Yao et al. ${ }^{66}$ for the preparation of a flavone library. The functionalized flavone 297 was prepared in solution phase by classical Claisen condensation, mixed acid nitration and oxidative cyclization reaction with iodine-DMSO. Then, this flavone $\mathbf{2 9 7}$ was employed as scaffold for the synthesis of a combinatorial library in solid phase (Scheme 47). The linker 296 was constructed by coupling of Fmoc-glycine 295 onto Rink resin, followed by Fmoc deprotection. After that, the flavone $\mathbf{2 9 7}$ was readily attached to the resin 296 using 1,3-diisopropylcarbodiimide (DIC). The subsequent aromatic nucleophilic substitution was performed with $1 \mathrm{~mol} \mathrm{~L}^{-1}$ phenols, mercaptans, or secondary amines in 25\% diisopropylethylamine (DIPEA)/ $N, N^{\prime}$-dimethylformamide (DMF) furnishing 299. The aryl nitro group was then reduced with tin(II) chloride to aryl amine 300, which was employed for the construction of different heterocyclic rings. For example, treatment with $1,1^{\prime}$-carbonyldiimidazole (CDI), followed by cleavage from the resin with triflouracetic acid -TFA furnished a benzimidazolone flavonoid $\mathbf{3 0 1}$

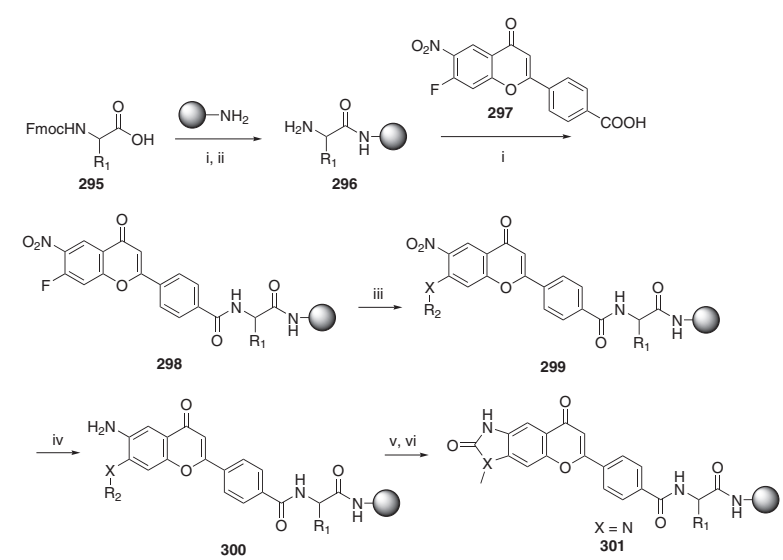

Reagents and conditions: i) HOBt/DIC, DMF, r.t.; ii) $20 \%$ piperidine/ DMF; iii) $1 \mathrm{~mol} \mathrm{~L}^{-1}$ phenol, mercaptan or amine, 25\% DIPEA/DMF, r.t.; iv) $2 \mathrm{~mol} \mathrm{~L}^{-1} \mathrm{SnCl}_{2}$, DMF, r.t.; v) CDI, $\mathrm{CH}_{2} \mathrm{Cl}_{2}$, r.t.; vi) $95 \% \mathrm{TFA}$, r.t.

Scheme 47.

Arai et $a l .{ }^{67}$ developed an efficient one-pot synthesis of chromone and flavonoid derivatives bearing heterocyclic units by Michael aldol reaction. They have also examined the onepot reactions in the solid phase by attaching an acetophenone derivative to (4-methoxyphenyl)diisopropylsilylpropyl polystyrene beads leading to resin $\mathbf{3 0 2}$. The use of substituted benzaldehydes and subsequent addition of heterocyclic aldehydes gave 3-pyridyl-substituted flavones 303. To introduce an additional point of diversity into the molecules, Suzuki-Miyaura coupling was performed, followed by cleavage from the resin, furnishing flavone $\mathbf{3 0 5}$ in good overall yields and high purity (Scheme 48). 


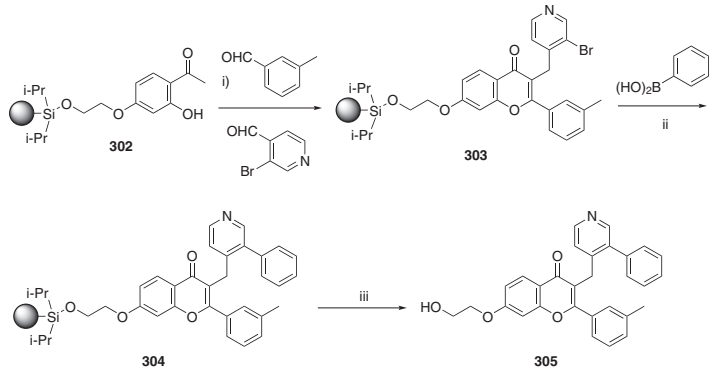

Reagents and conditions: i) $\mathrm{KOH}, \mathrm{EtOH}, 40{ }^{\circ} \mathrm{C}$; ii) $\mathrm{Pd}_{2}(\mathrm{dba})_{3}, \mathrm{NaOMe}$, $\mathrm{THF} / \mathrm{H}_{2} \mathrm{O}, 60^{\circ} \mathrm{C}, 24 \mathrm{~h}$; iii) $2 \% \mathrm{HCl}$, dioxane, 3 h, r.t.; $1 \mathrm{~N} \mathrm{NaOH}$

\section{Scheme 48.}

Chalcones are known to possess some pharmacological activities, among them antitumor. The synthesis of new pirrolobenzodiazepine-chalcones conjugates by SPOS has been achieved. ${ }^{68}$ The authors used the molecular hybridization strategy, combining chalcone (which binds to tubulin, preventing the proliferation of microtubules) to pyrrolobenzodiazepine, a compound that targets the minor groove of DNA. The divergent synthetic pathway is depicted in Scheme 49 and the synthesis started with the coupling of 2-hydroxyacetophenone $\mathbf{3 0 6}$ with Merrifield resin $\left(\mathrm{NaH}\right.$, dry $\left.\mathrm{DMF}, 50-60{ }^{\circ} \mathrm{C}, 48 \mathrm{~h}\right)$, followed of aldolisation with vanillin to afford the ketone-bound 308 ( $\mathrm{NaOMe} / \mathrm{THF} / \mathrm{MeOH}$, r.t., 4 days). The starting material 309 is prepared in solution and coupled with the resin intermediate $\mathbf{3 0 8}$ in the presence of $\mathrm{K}_{2} \mathrm{CO}_{3}$. Simple intramolecular aza-Wittig reductive cyclization process afforded compounds-bound $\mathbf{3 1 1}$ and 312, which

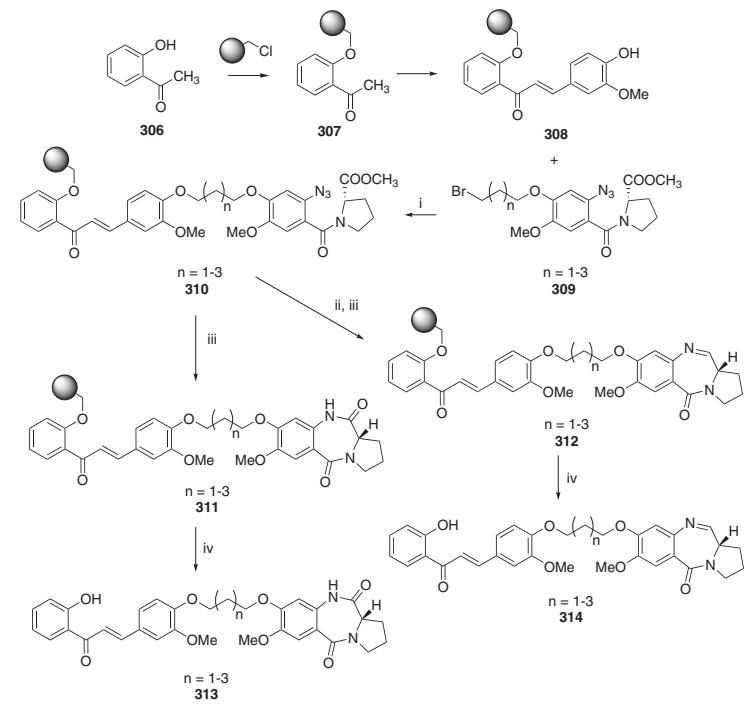

Reagents and Conditions: (i) $\mathrm{K}_{2} \mathrm{CO}_{3}$, dry $\mathrm{DMF}, 50{ }^{\circ} \mathrm{C}, 48 \mathrm{~h}$; (ii) diisobutylaluminium hydride (DIBAL)- $\mathrm{H}$, dry $\mathrm{CH}_{2} \mathrm{Cl}_{2},-78{ }^{\circ} \mathrm{C}, 2 \mathrm{~h}$; (iii) $\mathrm{PPh}_{3}$, dry toluene, r.t., 16 h; (iv) TFA/ $\mathrm{CH}_{2} \mathrm{Cl}_{2}$ (1:1), r.t., 2 h, 65-78\%. are released from the resin by employing TFA/ $\mathrm{CH}_{2} \mathrm{Cl}_{2}$ at r.t., in $2 \mathrm{~h}$.

\section{Polyamines}

Polyamines are organic polycations present in all cells and biologic liquids of live organisms that play an important role in control the general mechanism of the cellular proliferation. Putrescine is involved in many important biological processes such as embryogenesis and proliferation of normal or cancer cells while spermine, a putrescine metabolite, is known to inhibit cellular proliferation. In function of its considerable relation with the mechanisms involved in the proliferative process, the enzymes of the polyamines metabolism are potential targets for the design of new anticancer drugs and the knowledge of the mechanism implicated in the transport of polyamines can allow the development of polyamines analogues. ${ }^{69}$ Furthermore, these pathways contain enzymes that can be harvested as powerful biocatalysts for the synthesis of both new drugs and existing blockbuster therapeutics. All of these considerations have led medicinal chemists to employ the polyamine core as building block to design several small libraries of compounds combining heterocycle natural products scaffolds and polyamines.

An interesting divergent approach to built polyamines and polyamines derivatives was published by Manov and Bienz $^{70}$ employing the Merrifield resin and protected amines. They synthesized a library of 28 polyamines in which Scheme 50 depicted part of the synthesis. The Merrifield resin was modified with primary amines $\mathbf{3 1 5}$ and rapidly dialkylated. After selective deprotection of either of the two terminal amines, the specific prolongation or derivatization of the resin-bound triamines was performed. The resulting polyamines $\mathbf{3 2 5 - 3 2 9}$ were easily released from the polymer by treatment with 1-chloroethyl chloroformate (ACE-Cl) and subsequent methanolysis.

Uriac and co-workers ${ }^{71}$ have published the solidphase synthesis of a small set based on a natural

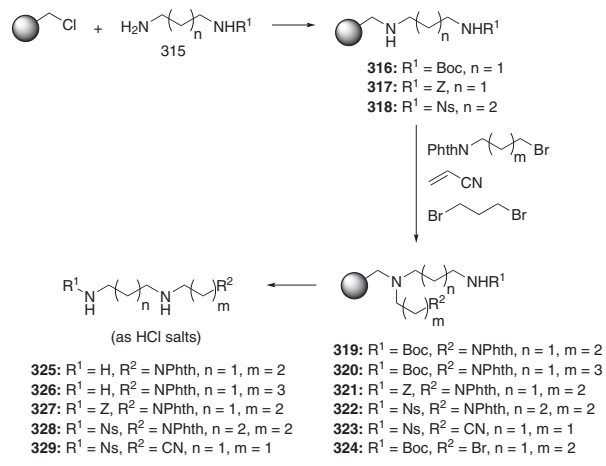

Scheme 50. 
lichen dibenzofurane derivative, usnic acid 335a-335f (Scheme 51). The authors took advantage of the antibacterial activity of usnic acid amino derivatives and they functionalized this dibenzofuran with polyamines in order to improve the antibacterial activity and to overcome their poor hydrosolubility.

Two sets of usnic acid derivatives polyaminated were synthesized by a split-and-mix method using SynPhase supports. Scheme 51 depicts one set of usnic acid triamines derivatives. SynPhase Lanterns supports were activated under anhydrous conditions with 4-nitrophenylchloroformate in the presence of $\mathrm{N}$-methylmorpholine, then reacted with commercial amino alcohols ( $\mathrm{n}=3-5$ ), affording supports 331. The supports 331 were pooled for the mesylation (332) then divided into four pools for the nucleophilic displacement by various diamines, and led to supported triamines $\mathbf{3 3 3}$. The supports 333 were mixed in two batches for the condensation with usnic acid and then the products $\mathbf{3 3 5} \mathbf{a}-\mathbf{3 3 5 f}$ were delivery from the supports in acid conditions. The products were obtained in good yield (30-40\%) and purity (87\%).

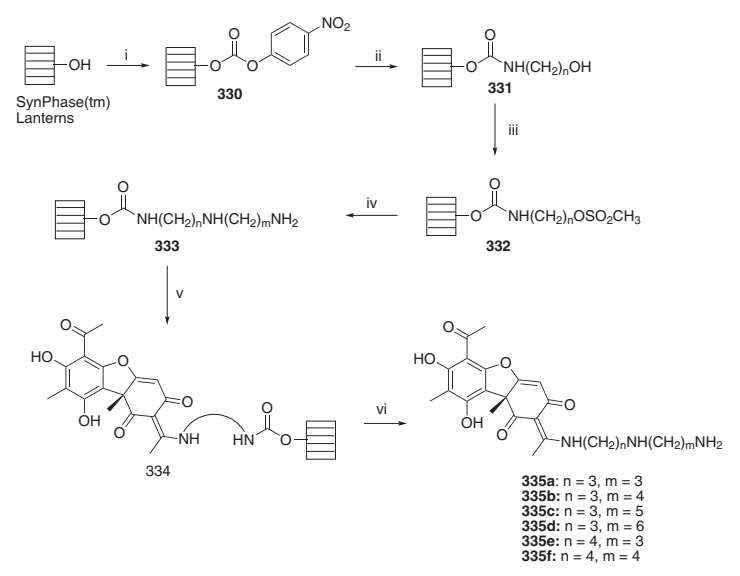

Scheme 51.

An elegant strategy to synthesize and test a mixture based chiral heptaamine library 338-339 $(34,012,170$ compounds) against $\mu$ opioid receptor, was recently developed by Houghten and co-workers. ${ }^{72}$ The authors prepared and screened the library using a Positional Scanning Synthetic Combinatorial Library (PS-SCLs) as strategy, which is composed by one sublibrary for each variable position. The solid-phase synthesis was performed starting with the polyamides reduction which consisting of a $72 \mathrm{~h}$ treatment of resin-bound peptides 336 with $\mathrm{BH}_{3}$-THF at $65{ }^{\circ} \mathrm{C}$ (Scheme 52).

A method for the synthesis of cyclic polyamines based on solid-phase chemistry has been reported..$^{73}$ The use of SPOS to obtain the cyclic polyamines was selected by the authors because the products and intermediates are very polar, which

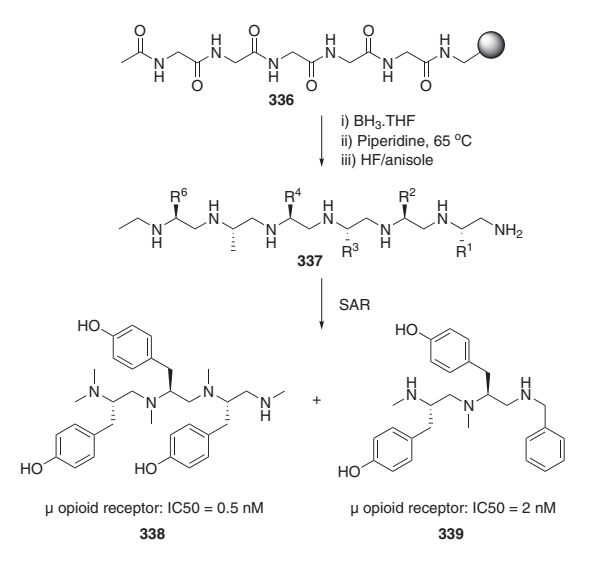

Scheme 52.

makes it difficult to purification, and to avoid the dimerization and polymerization in the macrocyclization step, due to the high dilutions necessary for their enforcement. Scheme 53 illustrates the selected route. The linear polyamines 340 and 342 have been synthesized stepwise on solid support in a convergent manner using Merrifield resin as solid support. Cyclisations on the resins were effected conventionally by direct intramolecular $\mathrm{S}_{N^{2}}$ reactions between sulphonylprotected terminal amino groups and primary alkyl bromides under basic conditions. The release of products from the resin was carried out by treatment with ACE-Cl followed by methanolysis.

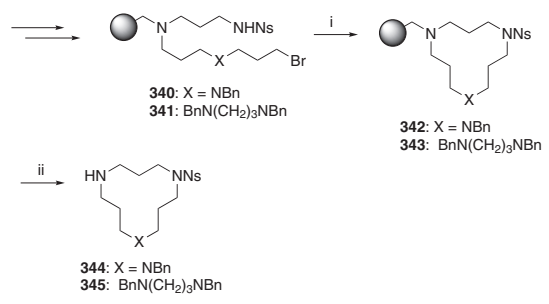

Reagents and conditions: i) $\mathrm{Cs}_{2} \mathrm{CO}_{3}$, DMF, $50{ }^{\circ} \mathrm{C}$; ii) ACE-Cl, DIEA, DCE, then $\mathrm{MeOH}$, reflux.

Scheme 53.

\section{Others}

Lactones are important classes of organic compounds due to their high occurrence in nature, and also because they are versatile building blocks in the synthesis of a wide range of natural and synthetic products. Macrolides are a class of antibiotic compounds that contain a large lactone (macrolide) ring of 12 to 16 atoms and several sugars linked to the ring. Sowin and co-worker ${ }^{74}$ published the first example of a library that employs the macrolide core as a template for combinatorial synthesis (Scheme 54). The synthesis was carried out using the aldehyde $\mathbf{3 4 7}$ as starting material, this core is accessible in large quantities 
from 6-O-allyl-erythromycin A. For the library synthesis they used aminonomethylpolystyrene resin containing a fluorine tag and an extended modified Wang type linker. The library introduces three sites of diversity to macrolide scaffold via reductive aminations.
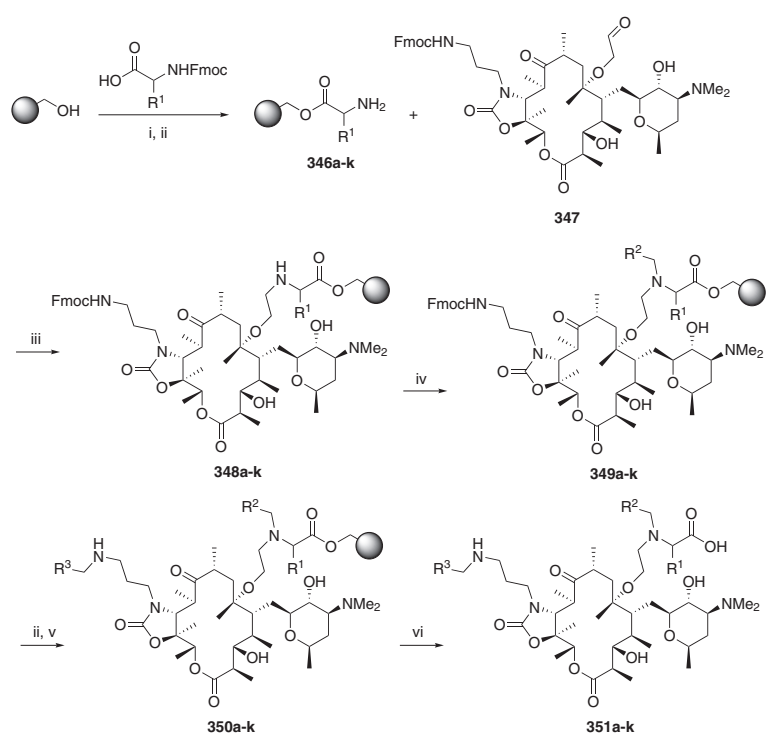

Reagents and conditions: i) DIC, DMAP, $\mathrm{CH}_{2} \mathrm{Cl}_{2} / \mathrm{THF}$; ii) $20 \%$ piperidine/ DMF ( $2 \mathrm{x})$; iii) $10 \% \mathrm{AcOH} / \mathrm{DMF}$, wash, $\mathrm{NaCNBH}_{3}, 10 \% \mathrm{AcOH} / \mathrm{DMF}$; iv) $\mathrm{R}^{2} \mathrm{CHO}, 10 \% \mathrm{AcOH} / \mathrm{DMF}, \mathrm{NaCNBH}_{3}$; v) $\mathrm{R}^{3} \mathrm{CHO}, 10 \% \mathrm{AcOH} / \mathrm{DMF}$, wash, $\mathrm{NaCNBH}_{3}, 10 \% \mathrm{AcOH} / \mathrm{DMF}$; vi) $90 \% \mathrm{TFA} / \mathrm{CH}_{2} \mathrm{Cl}_{2}$.

Scheme 54.

Pierres and co-workers ${ }^{75}$ related the SPOS of pyrones employing a hetero Diels-Alder approach (Scheme 55). In this work, the authors prepared a set of 5,6-dihydropyrones $\mathbf{3 5 4}$ grafting the Brassard diene $\mathbf{3 5 2}$ analogue on a modified Merrifield resin and reacted it with aldehydes or ketones. The diene $\mathbf{3 5 2}$ grafted on Wang resin proved to be more stable than the corresponding diene in solution which may offer significant short-cuts for the preparation of libraries of 5,6-dihydropyrones, with yields ranging from 20 to $55 \%$.

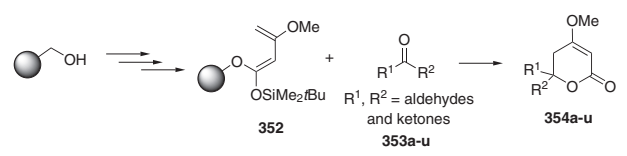

Scheme 55.

Benzoannelated butyrolactones (phthalides) are present in various natural products. Knepper and coworkes ${ }^{76}$ employed the Sakurai reaction for the solid-phase synthesis of phthalides (Scheme 56). For example, 2-formyl benzoic acids were immobilized on Merrifield resin using standard conditions. Treatment of resin $\mathbf{3 5 6}$ with allyltrimethyl silanes in the presence of five equivalents of titanium tetrachloride furnished the phthalides $\mathbf{3 5 8}$ in good yields and excellent purity. They have also demonstrated that asymmetric induction could be achieved by using chiral ligands.

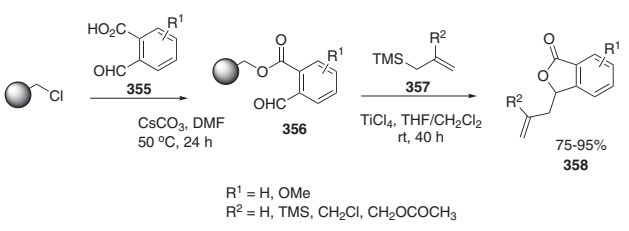

Scheme 56.

Gu et $a l .{ }^{77}$ reported the isolation, characterization and the solid-phase synthesis of microsporin A, a cyclic peptide with cytotoxic activity. The total solid-phase synthesis (Scheme 57) starts with the safety-catch sulfonamide linker resin 359. After several steps where amino acids were selectively added and unprotected, the intermediate $N$-Boc 363 was obtained. Activation of $\mathbf{3 6 3}$ by treatment with $\mathrm{ICH}_{2} \mathrm{CN}$ under basic conditions afforded the activated resin $\mathbf{3 6 4}$. Boc deprotection of $\mathbf{3 6 4}$ followed by cyclization and cleavage furnished the microsporin A $\mathbf{3 6 6}$.

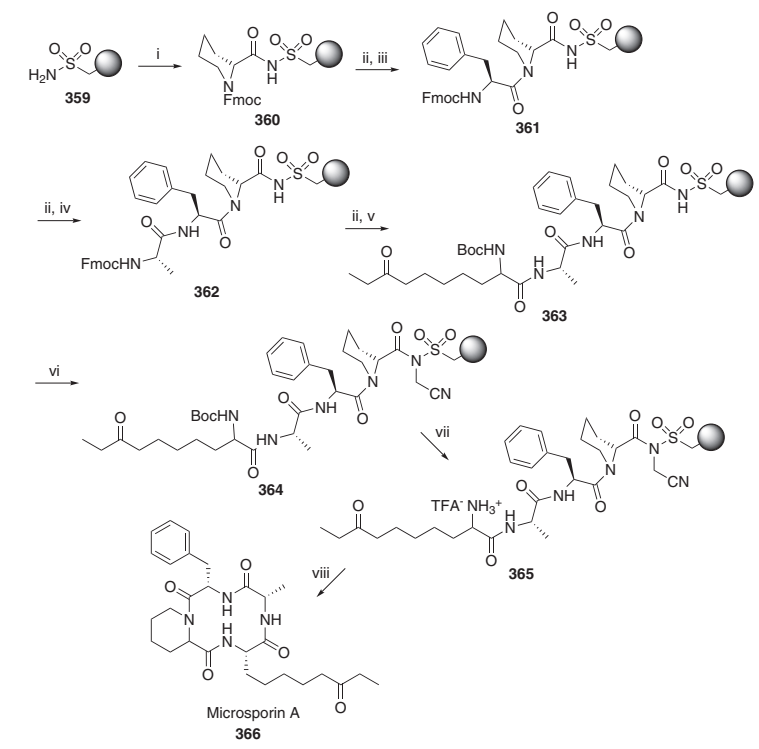

Reagents and conditions: i) Fmoc-D-Pip-OH, PyBOP, DIEA, $\mathrm{CH}_{2} \mathrm{Cl}_{2}$; ii) Piperidine, DMF; iii) Fmoc-Phe-OH, PyBOP, DIEA, NMP; iv) FmocAla-OH, PyBOP, DIEA, NMP; v) Boc-Aode-OH, PyBOP, DIEA, NMP; vi) $\mathrm{ICH}_{2} \mathrm{CN}$, DIEA, NMP; vii) TFA/ $\mathrm{CH}_{2} \mathrm{Cl}_{2}$; viii) $20 \%$ DIPEA, THF, reflux.

\section{Scheme 57.}

Distamycin 367 (Scheme 58) is a natural compound present in Streptomyces species which have an ability of recognize AT-rich sequences through noncovalently binding in the minor groove of B-form DNA. A combinatorial approach based on radiofrequency tagget split-and-mix methodology was exploited to prepare a 72 member library 
of distamicyn analogs in two points of diversification at the template. ${ }^{78}$ One of the diversity was at $N$-methylpyrrole-4formamido-2-yl unit, where it was replaced by novel biaryl motifs. The other one occurred when the amidine portion was changed by primary carboxamides after cleavage step from solid support by acid hydrolysis. The solid support employed was the easily available Fmoc-protected Rink Amide SynPhase Lanterns. The authors have developed an efficient coupling-cycle protocol on solid-phase based on standard methods for both assembly of the heteroaromatic polyamide chain and for the Suzuki-Miyaura crosscoupling reaction.
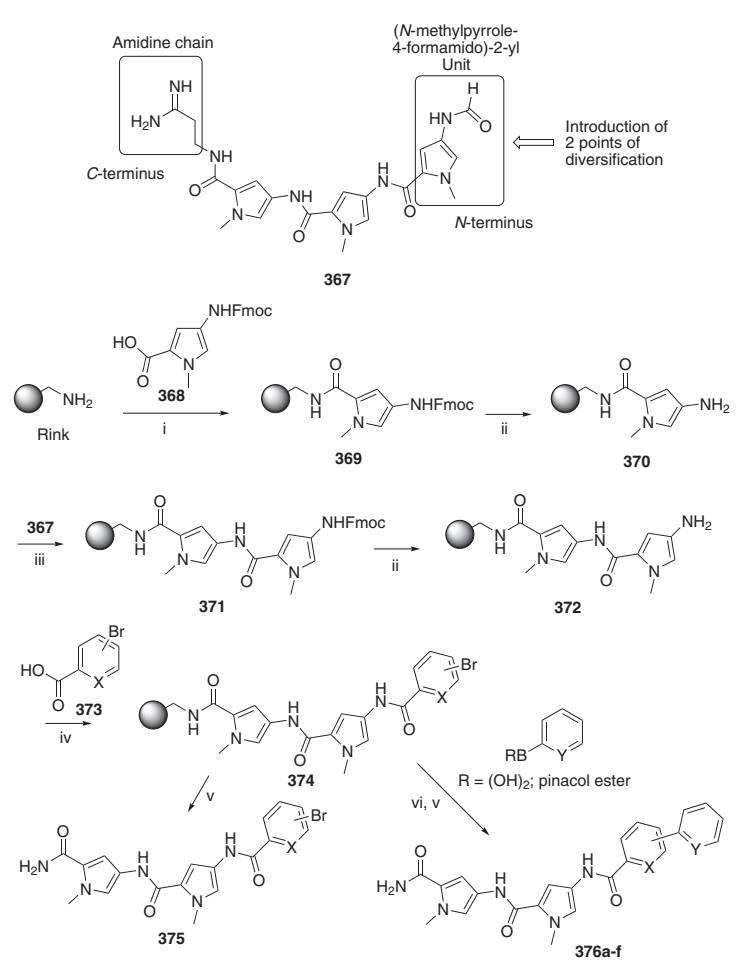

Reagents and conditions: i) $368\left(0.2 \mathrm{~mol} \mathrm{~L}^{-1}\right)$, $\mathrm{HOBt}(0.2 \mathrm{M})$, DIC $\left(0.2 \mathrm{~mol} \mathrm{~L}^{-1}\right)$, dry $\mathrm{DMF} / \mathrm{CH}_{2} \mathrm{Cl}_{2}(50 / 50), 12 \mathrm{~h}$; ii) $80 \%$ Piperidine/ DMF, $30 \mathrm{~min}(\times 2)$; iii) $10\left(0.2 \mathrm{~mol} \mathrm{~L}^{-1}\right)$, HOBt $\left(0.2 \mathrm{~mol} \mathrm{~L}^{-1}\right)$, DIC $\left(0.2 \mathrm{~mol} \mathrm{~L}^{-1}\right)$, dry DMF/ $\mathrm{CH}_{2} \mathrm{Cl}_{2}(50 / 50), 1.5 \mathrm{~h}(\times 2)$; iv) 373 (carboxylic acids) $\left(0.2 \mathrm{~mol} \mathrm{~L}^{-1}\right)$, HOBt $\left(0.2 \mathrm{~mol} \mathrm{~L}^{-1}\right)$, DIC $\left(0.2 \mathrm{~mol} \mathrm{~L}^{-1}\right)$, dry DMF/ $\mathrm{CH}_{2} \mathrm{Cl}_{2}(50 / 50), 1.5$ h, r.t. $(\times 2)$; v) $50 \%$ TFA/ $\mathrm{CH}_{2} \mathrm{Cl}_{2}, 1 \mathrm{~h}$; vi) boronic acid/ esters $(0.5 \mathrm{M}), \mathrm{Pd}\left(\mathrm{PPh}_{3}\right)_{4}\left(0.02 \mathrm{~mol} \mathrm{~L}^{-1}\right), \mathrm{Na}_{2} \mathrm{CO}_{3}\left(0.25 \mathrm{~mol} \mathrm{~L}^{-1}\right), \mathrm{DMF} /$ $\mathrm{H}_{2} \mathrm{O}(90 / 10), 80^{\circ} \mathrm{C}, 16 \mathrm{~h}$.

\section{Scheme 58.}

\section{Conclusions}

The application of combinatorial chemistry science has revolutionized the medicinal chemistry paradigms, as well as high-throughput screening, chemical lead optimization, library purification and post purification sample handling, at the same time as in vitro and in vivo drug metabolism and pharmacokinetic assays. ${ }^{79}$ While there are several ways to conduct high-throughput synthesis, combinatorial chemistry is by far the dominant activity leading to new diversity in compound libraries. ${ }^{80}$ In a recent review, Dolle et al. ${ }^{81}$ described 505 libraries and 30 molecular probes extracted from 490 literature citations in 2008. Several technologies alongside the solid-phase organic synthesis (SPOS) has emerged in recent years aiming to facilitate the rapid generation of compound libraries, as for example microwave-assisted organic synthesis (MAOS) and continuous-flow organic synthesis. ${ }^{82}$

Though SPOS is now considered an established tool for synthetic chemists, the challenge of handle it as well as the traditional solution chemistry still remains so demanding as at the beginning of the 1990's. New solid supports and solidphase techniques also continue to emerge as well hundreds of reactions have been adapted to SPOS. Moreover, the reactions on solid support may be staggered, with several reports in the literature of large-scale synthesis. ${ }^{83}$ For instance, the industrial peptide synthesis is carry out on solidphase and can be adapted to synthesis of small compounds. Also, this technology can be extended to solution phase synthesis with the employment of polymer-support reagents, catalysts, and cleanup agents (scavengers), which facilitate reactions of substrates in solution. Employing SPOS to build compounds with multiple stereocenters with natural building blocks or to prepare complex natural product libraries is also a very elegant approach to find new hits and have a great impact on drug development. ${ }^{84}$

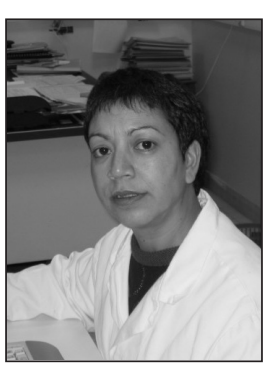

Vera Lucia Eifler-Lima has graduated in Pharmacy and received her Master Degree in Pharmaceutical Sciences (Federal University of Rio Grande do Sul - UFRGS). She has received her $P h D$ in Organic Chemistry from the Faculty of Pharmacy (University of Rennes I, France, Professor Jean Huet). She is currently an Associate Professor in the Faculty of Pharmacy at UFRGS. She has experience in medicinal chemistry, with emphasis on organic synthesis. Her research interests include new strategies of synthesis for use in combinatorial chemistry, and development and obtaining antiparasitic and antitumor hits. She is the head of the CNPq Research Group on Medicinal Organic Synthesis and has been a long-time member of the Brazilian Chemical Society.

Cedric Stephan Graebin has received his PhD Degree from the Federal University of Rio Grande do Sul (UFRGS - 2008), and completed his postdoctoral training with Professor Dr. Jorge A. Guimarães (UFRGS - 2009). 


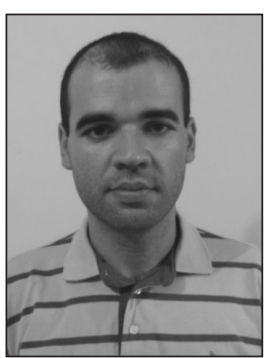

He is an Adjunct Professor at the Department of Chemistry, Rio de Janeiro Federal Rural University. His research interest is the synthesis of new pharmacologically active compounds from both solution and solid-phase synthesis.

Flavia De Toni Uchoa graduated

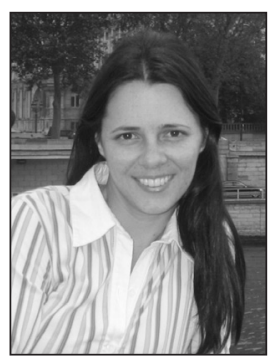

in Pharmacy from the Federal University of Rio Grande do Sul (1997). She received her Master Degree in Bioactive Products of Biotechnology from the Federal University of Pernambuco (2004) and a PhD Degree in Medicinal Chemistry and Pharmacology from the same institution. She completed her Postdoctoral training at UFRGS in 2009 and works mainly with the synthesis and preclinical studies of candidate drugs.

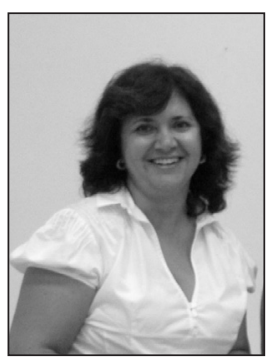

Arlene G. Corrêa received her PhD from the Federal University of São Carlos (1991) and completed her Postdoctoral training with Professor Paul A. Wender (Stanford University, CA, 1997). She is an Associate Professor in the Department of Chemistry at the University Federal of São Carlos. Her research interests are isolation, identification and synthesis of insect pheromones; synthesis of bioactive natural products and analogs employing combinatorial chemistry technologies and green chemistry. She is a member of the Brazilian Chemical Society and the American Chemical Society.

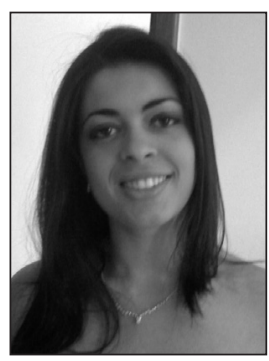

Patricia Domingos Duarte, graduated in Chemistry from the Federal University of São Carlos (2007). She is currently a PhD student in Organic Chemistry at the same institution, working on the asymmetric synthesis of alkaloids under the supervision of Professor Arlene G. Corrêa.

\section{References}

1. Fenniri, H.; ed. In Combinatorial Chemistry: Pratical Approach. Oxford University Press: Oxford, 2000; Dias, R. L. A.; Correa, A. G.; Quim. Nova 2001, 24, 236.
2. Merrifield, R. B.; J. Am. Chem. Soc. 1963, 85, 2149; Früchtel, J. S.; Jung, G.; Angew. Chem. Int. Ed. Engl. 1996, 35, 17; Thompson, L. A.; Elmann, J. A.; Chem. Rev. 1996, 96, 555; Booth, S.; Hermkens, P. H. H.; Ottenheijm, H. C. J.; Rees, D. C.; Tetrahedron 1998, 54, 15385.

3. Marquardt, M.; Eifler-Lima, V. L.; Quim. Nova, 2001, 24, 846.

4. Delgado, M.; Janda, K. D.; Curr. Org. Chem. 2002, 6, 1031.

5. Rates, S. M. K. Toxicon 2001, 39, 603-613.

6. Verdine, G. L.; Nature 1996, 384, 11.

7. Newman, D. J.; Cragg, G.M.; J. Nat. Prod. 2007, 70, 461.

8. Rouhi, M. A.; Chem. Eng. News 2003, 81, 77.

9. Wang, H.; Ganesan, A.; J. Comb. Chem. 2000, 2, 186.

10. Sato, S.; Kubota, Y.; Kumagai, H.; Kumazawa, T.; Matsuba, S.; Onodera, J.; Suzuki, M.; Heterocycles 2000, 53, 1523.

11. Wang, H.; Sim, M. M.; J. Nat. Prod. 2001, 64, 1497.

12. Pelish, H.; Westwood, N.; Feng, Y.; Kirchhausen, T.; Shair, M.; J. Am. Chem. Soc. 2001, 123, 6740.

13. Huang, X.; Liu, Z.; J. Org. Chem. 2002, 67, 6731.

14. Baxendale, I. R.; Ley, S. V.; Piutti, C.; Angew. Chem. Int. Ed. 2002, 41, 2194.

15. Baxendale, I. R.; Brusotti, G.; Matsuoka, M.; Ley, S. V.; J. Chem. Soc., Perkin Trans. I 2002, 143.

16. Finaru, A.; Berthault, A.; Besson, T.; Guillaumet, G.; BerteinaRaboin, S.; Org. Lett. 2002, 4, 2613.

17. Nielsen, T. E.; Meldal, M.; J. Org. Chem. 2004, 69, 3765.

18. Marfil, M.; Albericio, F.; Álvarez M.; Tetrahedron 2004, 60, 8659.

19. Cironi, P.; Cuevas, C.; Albericio, F.; Álvarez, M.; Tetrahedron 2004, 60, 8669.

20. Knepper, K.; Ziegert, R. E.; Brase, S.; Tetrahedron 2004, 60, 8591.

21. Gan, Z.; Reddy, P. T.; Quevillon, S.; Couve-Bonnaire, S.; Arya, P.; Angew. Chem. Int. Ed. 2005, 44, 1366.

22. Adriaenssens, L. V.; Austin, C. A.; Gibson, M.; Smith, D.; Hartley, R. C.; Eur. J. Org. Chem. 2006, 4998.

23. Lee, S.; Park, S. B.; J. Comb. Chem. 2006, 8, 50.

24. Doi, T.; Hoshina, Y.; Mogi, H.; Yamada, Y.; Takahashi, T.; J. Comb. Chem. 2006, 8, 571.

25. Kamal, A.; Shankaraiah, N.; Devaiah, V.; Reddy, K. L.; Tetrahedron Lett. 2006, 47, 9025.

26. Baxendale, I. R.; Deeley, J.; Griffiths-Jones, C. M.; Ley, S. V.; Saaby, S.; Tranmer, G. K.; Chem. Commun. 2006, 2566.

27. Krchnak, V.; Waring, K. R.; Noll, B. C.; Moellmann, U.; Dahse, H.; Miller, M. J.; J. Org. Chem. 2008, 73, 4559.

28. Calver, A.; Main, C. A.; Petersson, H. M.; Rahman, S. S.; Hartley, R. C.; Tetrahedron 2008, 64, 901.

29. Worlikar, S. A.; Neuenswander, B.; Lushington, G. H.; Larock, R. C.; J. Comb. Chem. 2009, 11, 875.

30. Duarte, M.; Stedile, G.; Pazinatto, M.; Oliveira, E. R.; EiflerLima, V. L.; Lett. Org. Chem. 2009, 6, 90.

31. Chen, K.; Phil, S.; Nature 2009, 459, 824. 
32. Wang, G.; Tang. W.; Bidigare, R. R. In Natural Products - Drug Discovery and Therapeutic Medicine; Zhang, L.; Demain, A. L., eds.; Humana Press: Totowa, 2005, ch. 9.

33. Maltais, R.; Tremblay, M. R.; Poirier, D. ; J. Comb. Chem. 2000, 2,604 .

34. Tremblay, M. R.; Poirier, D.; Tetrahedron Lett. 1999, 40, 1277.

35. Tremblay, M. R.; Poirier, D.; J. Comb. Chem., 2000, 2, 48.

36. Kufe, D. W.; Pollock, R. E.; Weichselbaum, R. R.; Bast, R. C., Jr.; Gansler, T. S.; Holland, J. F.; Frei III, E., eds. In Cancer Medicine Hamilton, BC Decker: Canada, 2003.

37. Xiao, X. Y.; Li, R.; Zhuang, H.; Ewing, B.; Karunaratne, K.; Lillig, J.; Brown, R.; Nicolaou, K. C.; Biotechnol. Bioeng. 2000, 71,44 .

38. Hijikuro, T. D.; Takahashi, T.; J. Am. Chem. Soc. 2001, 123, 3716.

39. Moore, K. S.; Wehrli, S.; Roder, H.; Rogers, M.; Forrest, J. N.; McCrimmon, D.; Zasloff, M.; Proc. Natl. Acad. Soc. 1993, 90, 1354.

40. Chitkul, B.; Atrash, B.; Bradley, M.; Tetrahedron Lett. 2001, 42,6211 .

41. Hanazawa, T.; Wada, T.; Matsuda, S.; Okamoto, S.; Sato, F.; Org. Lett. 2001, 3, 3975.

42. Jagtap, P. G.; Baloglu, E.; Barron, D. M.; Bane, S.; Kingston, D. G.; J. Nat. Prod. 2002, 65, 1136.

43. Miyaoka, H.; Kajiwara, Y.; Yamada, Y.; Tetrahedron Lett. 2000, $41,911$.

44. Brohm, D.; Philippe, N.; Metzger, S.; Bhargava, A.; Müller, O.; Lieb, F.; Waldmann, H.; J. Am. Chem. Soc., 2002, 124, 13171.

45. Saleem, M.; Murtazaa, I.; Witkowskya, O.; Kohla, A. M.; Maddodi, N.; Biochem. Biophys. Res. Comm. 2009, 388, 576.

46. Geetha, T.; Varalakshmi, P.; J. Ethnopharmacol. 2001, 76, 77.

47. Ziegler, H. L.; Stærk, D.; Christensen, J.; Hviid, L.; Hägerstrand, H.; Jaroszewski, J. W.; Antimicrob. Ag. Chemother. 2002, 46, 1441.

48. Srinivasan, T.; Srivastava, G.K.; Pathak, A.; Batra, S.; Raj, K.; Singh, K.; Puri, S.K.; Kundu, B.; Bioorg. Med. Chem. Lett. 2002, 12, 2803.

49. Pathak, A.; Singh, S. K.; Biabani, M. A. Farooq; Kulshreshtha, D. K.; Puri, S. K.; Srivastava, S.; Kundu, B.; Comb. Chem. High Through. Screen. 2002, 5, 241.

50. Ciobanu, L. C.; Poirier, D.; J. Comb. Chem., 2003, 5, 429.

51. Subramanian, T.; Wang, Z.; Troutman, J. M.; Andres, D. A.; Spielmann, H.P.; Org. Lett. 2005, 7, 2109.

52. Bod'E, C. A.; Muller, C. P.; Madder, A.; J. Pept. Sci. 2007, 13, 702.

53. Yu, X.; Wang, S.; Chen, F.; J. Comb. Chem. 2008, 10, 605.

54. Juan, M. E.; Planas, J. M.; Ruiz-Gutierrez, V.; Daniel, H.; Wenzel, U.; Br. J. Nutr. 2008, 100, 36.

55. Parra, A.; Rivas, F.; Lopez, P. E.; Garcia-Granados, E.; Martinez, A.; Albericio, F.; Marquez, N.; Muñoz, E.; Bioorg. Med. Chem. 2009, 17, 1139.
56. Nicoletti, D.; Mouriño, A.; Torneiro, M.; J. Org. Chem. 2009, $74,4782$.

57. Song, A.; Lam, K. S.; Tetrahedron 2004, 60, 8605; Song, A.; Zhang, J.; Lebrilla, C. B.; Lam, K. S.; J. Comb. Chem. 2004, 6,604 .

58. Peuchmaur, M.; Lisowski, V.; Gandreuil, C.; Maillard, L. T.; Martinez, J.; Hernandez, J-F.; J. Org. Chem. 2009, 74, 4158.

59. Brueggemeier, R. W.; Gu, X. J.; Mobley, J. A.; Joomprabutra, S.; Bhat, A. S.; Whetstone, J. L.; Ann. New York Acad. Sci. 2001, 948, 51.

60. Hall, D. G.; Manku, S.; Wang, F.; J. Comb. Chem. 2001, 3, 125; Horton, D. A.; Bourne, G. T.; Smythe, M. L.; Chem. Rev. 2003, 103, 893; Ziegert, R. E.; Toräng, J.; Knepper, K.; Bräse, S.; J. Comb. Chem. 2005, 7, 148.

61. Harikrishnan, L. S.; Showalter, H. D. H.; Tetrahedron 2000 , $56,515$.

62. Bhat, A. S.; Whetstone, J. L.; Brueggemeier, R. W.; J. Comb. Chem. 2000, 2, 597.

63. Nicoloau, K. C.; Pfefferkorn, J. A.; Roecker, A. J.; Cao, G. Q.; Barluenga, S.; Mitchell, H.; J. Am. Chem. Soc. 2000, 122, 9939.

64. Cheng, M. S.; Li, R. S.; Kenyon, G.; Chin. Chem. Lett. 2000, 11,851 .

65. Huang, X.; Tang, E.; Xu, W.; Cao, J.; J. Comb. Chem. 2005, 7, 802.

66. Yao, N.; Song, A.; Wang, X.; Dixon, S.; Lam, K. S.; J. Comb. Chem. 2007, 9, 668.

67. Arai, M. A.; Sato, M.; Sawada, K.; Hosoya, T.; Ishibashi, M.; Chem. Asian J. 2008, 3, 2056.

68. Kamal, A.; Shakaraiah, N.; Prabhakar, S.; Reddy, C. R.; Markandeya, N.; Reddy, K. L.; Devaiah, V.; Bioorg. Med. Chem. Lett. 2008, 18, 2434.

69. Delcros, J. G.; Tomasi, S.; Duhieu, S.; Foucault, M.; Martin, B.; Le Roch, M.; Eifler-Lima, V. L.; Renault, J.; Uriac, P.; J. Med. Chem. 2006, 49, 232; Casero, R. A.; Woster, P. M.; J. Med. Chem. 2009, 52, 4551.

70. Manov, N.; Bienz, S.; Tetrahedron 2001, 37, 7893.

71. Tomasi, S.; Picard, S.; Lainé, C.; Babonneau, V.; Goujeon, A.; Boustie, J.; Uriac, P.; J. Comb. Chem. 2006, 8, 11.

72. Nefzi, A.; Ostresh, J. M.; Appel, J. R.; Bidlack, J.; Dooley, C. T.; Houghten, R. A.; Bioorg. Med. Chem. Lett.. 2006. 16, 4331.

73. Bisegger, P.; Manov, N.; Bienz, S.; Tetrahedron. 2008, 64, 7531.

74. Akritopoulou-Zanze, I; Sowin, T. J.; J. Comb. Chem. 2001, 3, 301.

75. Pierres, C.; George, P.; Hijfte, L.; Ducep, J. B.; Hibert, M.; Mann. A.; Tetrahedron Lett. 2003, 44, 3645.

76. Knepper, K.; Zieger, R. E.; Bräse, S.; Tetrahedron 2004, 60, 8591.

77. Gu, W.; Cueto, M.; Jensen, P. J.; Fenical, W.; Silverman, R. B.; Tetrahedron 2007, 63, 6535.

78. Brucoli, F.; Howard, P.; Thurston, D.; J. Comb. Chem. 2009, $11,576$. 
79. Kennedy, J. P.; Williams, L.; Bridges, T. M. R.; Daniels, N.; Weaver, D.; Lindsley; C. W. J. Comb. Chem. 2008, 10, 345.

80. Czarnik, A. W.; J. Comb. Chem., 2008, 10, 1.

81. Dolle, R. E.; Le Bourdonnec, B.; Goodman, A. J.; Morales, G. A.; Thomas, C. J.; Zhang, W.; J. Comb. Chem. 2009, 11, 739.

82. Boldt, G. E.; Dickerson, T. J.; Janda, K. D.; Drug Discov. Today 2006, 11, 143; Baxendale, I. R.; Hayward, J. J.; Ley, S. V.; Comb. Chem. High Throughput Screening 2007, 10, 802.

83. Ryba, T. D.; Depew, K. M.; Marcaurelle, L. A.; J. Comb. Chem. 2009, 11, 110 ; He, U.; Chan, T. H.; Org. Lett. 2007, 9, 2681;
Verlander, M.; Intl. J. Pept. Res. Therapeut. 2007, 13, 75; Prühs, S.; Dienter, C.; Blume, T.; Schültz, A.; Harre, M.; Neh, H.; Org. Proc. Res. Dev. 2006, 10, 441.

84. Moss, W.H.; Hurt, C.R.; Morales, G.A.; Mol. Divers. 2009, 13, 241.

Received: January 8, 2010

Web Release Date: May 27, 2010

FAPESP has sponsored the publication of this article. 